\title{
El martyrium de la Epístola XXV de Gregorio de Nisa. Nueva propuesta de restitución de edificio
}

\author{
Sergio Vidal Álvarez. UNED ${ }^{1}$ \\ The Martyrium of the Epistle XXV of Gregory of Nissa. New \\ Proposal of Restitution
}

\begin{abstract}
RESUMEN
A partir de la información que nos proporciona la Epístola XXV de Gregorio de Nisa (335-394/5 d.C.), se pretende restablecer el sistema de proporciones que pudo regir al martyrium que Gregorio pretende construir en Nisa (Capadocia) y del que no se conoce ninguna otra información. Según se indica en la epístola, el edificio debe seguir un esquema en planta de cruz griega con octógono central y cubierta cupulada, además de un peristilo, siguiendo los parámetros propios de la arquitectura cristiana martirial de la época.
\end{abstract}

PALABRAS CLAVE: Gregorio de Nisa, Martyrium, arquitectura cristiana tardoantigua.

\begin{abstract}
From the information given by the Epistle XXV of Gregory of Nissa (335-394/5 AD), we attempt to restore the system of proportions used to build the martyrium that Gregory plans to construct at Nissa (Capadoce), a building that we know only by this written source. As the Epistle notes, the building must follow a greek cross plan, with an octagon in the centre with a domed cover, plus a peristyle, following the regular parameters of the Christian martyrial architecture of the time.
\end{abstract}

\section{KEWORDS:}

Gregory of Nissa, Martyrium, Late Antique Christian Architecture.

La Epístola XXV de Gregorio de Nisa es sin duda un destacado testimonio escrito para el conocimiento y estudio de la edilicia de la Antigüedad Tardía, especialmente en lo referente a la percepción que de la misma tuvieron sus propios comitentes. Esta importancia radica principalmente en la rareza de referencias de este tipo en los escritos conocidos de la época, así como en la destacada posición

\footnotetext{
${ }^{1}$ svidal@geo.uned.es. El origen del presente estudio parte de la investigación realizada en el marco de los estudios de doctorado de la Universitat de Barcelona, siendo necesario agradecer el impulso y consejos recibidos en su momento por C. Godoy, así como la inestimable ayuda recibida de M. Figols para los cálculos matemáticos que desarrollamos. Debo agradecer también el apoyo de Y. Peña Cervantes, sin cuya labor no hubiera sido posible presentar, con el nivel de exactitud y detalle deseados, las planimetrías y alzados informatizados que ahora se aportan.
} 
del autor de texto, el obispo Gregorio de Nisa (ca. 335 Cesarea de Capadocia, ca. 394-395 Nisa), uno de los tres vértices del triángulo de los llamados «Padres Capadocios», junto a Basilio «Magno» (hermano mayor de Gregorio) y Gregorio Nacianceno (amigo de ambos).

La excepcionalidad a que hacemos referencia afecta a la naturaleza específica del texto puesto que, lejos de encontrarnos ante una mera descripción más o menos retórica de un edificio o un conjunto de edificios existentes -lo que lo incluiría en el grupo mucho más nutrido de escritos conocidos de carácter descriptivo-, el texto constituye un verdadero proyecto arquitectónico, refiriéndose a la planificación de la construcción de una obra ex nuovo, en unos términos sorprendentes por su concreción y precisión².

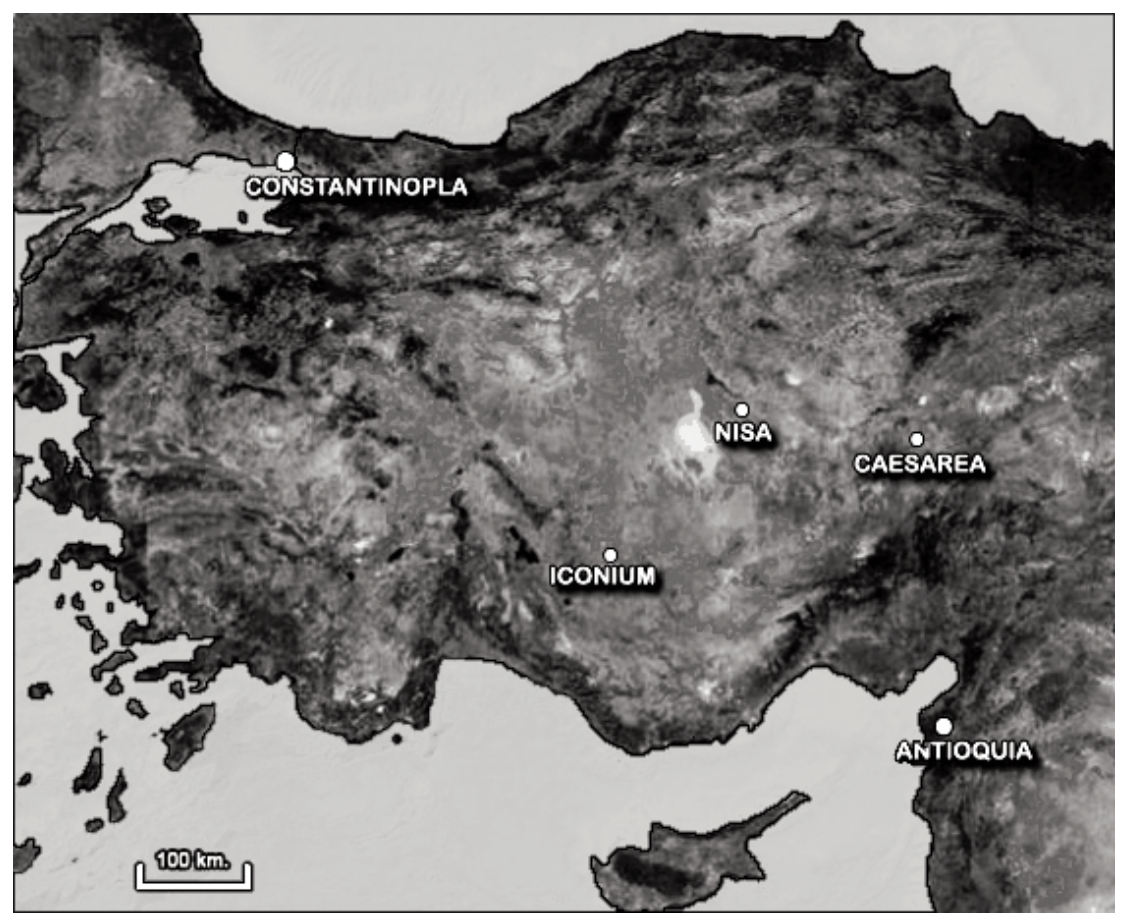

1. Mapa de Anatolia con indicación de las principales ciudades concernientes al texto (fuente: Google Maps), Modificado por el autor.

\footnotetext{
${ }^{2}$ Dicha escasez es revelada de manera explícita por C. Mango quien, además de recoger la Ep. XXV de Gregorio, aporta únicamente otros dos testimonios que se le puedan equiparar. Por una parte la Carta del emperador Constantino a Macario (obispo de Jerusalén), datada hacia el 326 y referente a la construcción de la iglesia del Santo Sepulcro, su financiación, tipo de revestimiento interno, etc. Por otra parte, la construcción de la catedral de Gaza (402-407), en el que el plano de la misma es enviado directamente desde Constantinopla por la emperatriz Eudoxia (esposa de Arcadio), al obispo local Porfirio. Se sabe también que Porfirio contrató como architektôn de la obra a un tal Rufino, natural de Antioquía. Para estos testimonios y su trascendencia vid. Mango, 1975, pp. 25-27, con bibliografía.
} 
Gregorio, obispo de Nisa (entre los años 372-376 primero y, posteriormente, del 377/378 al 394/395), escribe a Anfiloquio, obispo de Iconium (actual Konya, a unos $170 \mathrm{~km}$. al sudoeste de Nisa) (fig. 1), solicitándole mano de obra cualificada para la construcción en Nisa de un edificio martirial, detallando para tal efecto sus características y principales dimensiones.

No nos detendremos en los principales aspectos biográficos y literarios de Gregorio de Nisa, cuestiones a las que han dedicado su atención numerosos estudio$\mathrm{sos}^{3}$, sin embargo, debemos destacar de un modo particular sus viajes, considerando que en ellos conocería edificios cristianos de la relevancia de las construcciones de época constantiniana de Tierra Santa (complejo del Santo Sepulcro, etc.) o el Martyrium de San Babilás en Antioquia, sobre los que habremos de volver más adelante (vid. Infra). En referencia a su obra escrita, además de sus múltiples epístolas, entre las que se enmarca el texto que ahora nos ocupa, cabe destacar algunas de sus obras de carácter exegético, como el Comentario sobre los seis días de la Creación (Hexaémeron), el tratado Sobre la creación del hombre, o su Vida de Moisés ${ }^{4}$. Como veremos, el contenido de estos escritos podrá relacionarse con ciertos aspectos concernientes al sistema de proporciones de la construcción de Nisa.

Respecto a la Epístola XXV, nos ha sido transmitida a través de una única fuente manuscrita conocida, el Codex Laurentianus Mediceus plut., LXXXV, 13, fols. 243v-245v, de la Biblioteca Laurenciana de Florencia, escrito en griego y datado en el siglo XIII ${ }^{5}$. Pasquali, quien ha tratado con mayor profundidad la cuestión, sostiene que tanto dicho códice como otro en el Vaticano (el Codex Vaticanus graecus 424, de los siglos XIII-XIV, que no contiene la Ep. XXV), derivarían de un prototipo común que llama $\Gamma$, no posterior al siglo $I X^{6}$.

En cuanto a la datación de la epístola, el único terminus post quem seguro es el año 373, fecha en que su destinatario, Anfiloquio, es nombrado obispo de Iconium, siendo el terminus ante quem la fecha de la muerte del propio Gregorio, por tanto los años 394-395. Dentro de estos dos extremos, las fechas más común-

\footnotetext{
${ }^{3}$ Vid. especialmente Quasten, 1962, pp. 267-310; Altaner, 1956, pp. 268-271; Maraval, 1990, pp. 1552, Vives, 1991, pp. 7-19 y, más recientemente, Silvas, 2007, pp. 1-57. Es de consulta igualmente esencial el Diccionario sobre Gregorio de Nisa, de Mateo Seco - Maspero (eds.), 2010, con amplio repertorio bibliográfico.

${ }^{4}$ En esta última obra Gregorio, apartándose del modelo de Filón de Alejandría (ss. I a.C.-I d.C.), presenta la vida de Moisés como un proceso de ascensión mística hacia la «tiniebla luminosa» que culmina en el grado supremo de la comunión con Dios. Al respecto vid. Vives, op. cit., pp. 19-47, espec. 42-47, con bibliografía.

${ }^{5}$ Para el tema de la transmisión textual de las epístolas de Gregorio de Nisa, sus aspectos cronológicos, etc., vid. Maraval, op. cit., pp. 53-78, espec. pp. 69-77, para el grupo formado por las Epístolas IV a la XXX. Más recientemente Silvas, op. cit., 59-72.

${ }^{6}$ Pasquali, 1925, pp. LVI-LVIII. El mismo autor propone, además, que dicho códice $\Gamma$ junto con otro, el Cod. Patmensis 706, del siglo XI, derivarían de un prototipo anterior (que denomina X), del siglo IX, extremo que no es aceptado por la crítica posterior, por considerar improbable la existencia forzosa de un códice que agrupara, a modo de corpus, toda la producción epistolar de Gregorio de Nisa. No profundiza en esta cuestión la más reciente aportación de, Silvas, op. cit., pp. 68-72.
} 
mente aceptadas la sitúan hacia el 380 o el $382^{7}$ siempre, en todo caso, en un momento posterior al exilio que sufrió Gregorio entre los años 376-3778.

Las principales ediciones del texto griego de la epístola las debemos a Migne $(P G)^{9}$, Pasquali ${ }^{10}$ y Maraval ${ }^{11}$, destacando las traducciones francesa, a cargo del mismo Maraval ${ }^{12}$, la italiana de Criscuolo $^{13}$ y la más reciente inglesa de Silvas ${ }^{14}$, contando para la lengua española con la traducción de Teja ${ }^{15}$.

\section{CONTENIDO DE LA EPÍSTOLA XXV}

Uno de los primeros elementos que nos llama la atención en la Epístola es el hecho de que no sea la primera vez que Gregorio se dirige al mismo interlocutor sobre el tema, señalando que el proyecto de construcción del $\mu \alpha \rho \tau$ cí́ $\omega$ se encuentra en fase de ejecución ${ }^{16}$. No se informa sobre aspectos como la dedicación del edificio, pudiendo suponer que fuera una cuestión ya tratada en anteriores comunicaciones entre ambos obispos; en todo caso, las diversas propuestas formuladas al respecto no son concluyentes ${ }^{17}$. Por otra parte, destaca el hecho de que Gregorio se refiera al

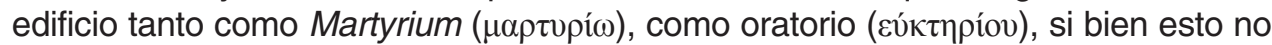
debe suponer una contradicción al ser la función principal del edificio la conmemoración de un mártir ${ }^{18}$.

El texto prosigue con una apropiada cita a San Pablo, fundador de la comunidad de Iconium, en su carta a los Filipenses (Fil. 1, 6), seguida de la petición que motiva la carta: la solicitud a Anfiloquio del envío de los obreros necesarios para poder ejecutar la obra del martyrium, lo que per se supone un testimonio de excepcional importancia respecto al fenómeno de la itinerancia de los grupos de obreros, siendo el

\footnotetext{
${ }^{7}$ Así especialmente Grabar, 1946, p. 151; Mango, op. cit., p. 26; Maraval, op. cit. pp. 288-289; Silvas, op.cit., p. 71.

${ }^{8}$ Por el contrario, para una datación anterior al exilio de Gregorio, hacia el 373-375 vid. Restle, 1979, p. 80; Klock, 1983, p. 165.

${ }^{9}$ Migne, PG, XLIV-XLVI, espec. vol. LXVI, cols. 1093-1100, edición del texto griego y su traducción al latín.

${ }^{10}$ Pasquali, op. cit., pp. 76-80.

${ }^{11}$ Maraval, op. cit., pp. 288-300 (texto griego y traducción francesa).

12 Ibid.

${ }^{13}$ Criscuolo, 1981.

${ }^{14}$ Silvas, op. cit., pp. 196-202.

15 Teja, 1991, pp. 67-69, con registro de las ediciones existentes de la epístola tanto en griego como en lenguas modernas, así como un compendio de la principal bibliografía.

${ }^{16}$ No se conserva referencia alguna anterior a la Epístola XXV sobre este mismo tema, pudiendo considerar que las diversas comunicaciones entre Gregorio y Anfiloquio pudieron ser tanto escritas como verbales.

${ }_{17}$ Los esfuerzos más claros en este sentido aparecen expresados en Keil, 1903, p. 78, n. 1, donde, sin embargo, no se llega a ninguna hipótesis concluyente.

${ }_{18}$ Para esta problemática vid. Godoy, 1995, pp. 70-74, donde a pesar de centrarse de un modo especial en Hispania y África, creemos que las conclusiones pueden ser, en este caso, aplicables a un edificio oriental. En el mismo sentido, vid. las consideraciones de Saxer, 1980 y Duval, 1988.
} 
motivo, a la luz de los datos de la propia epístola, de índole esencialmente económica.

Gregorio describe la estructura del edificio, con el fin de que Anfiloquio calcule sus dimensiones y así poder saber la cantidad de mano de obra que es necesario enviar a Nisa. De este modo, se indica la forma de la construcción: una cruz — tipo de planta propia para un martyrium - en la que, sin embargo, los cuatro brazos no se han de

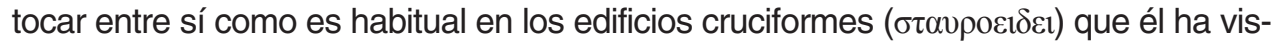
to en sus viajes. Uno de los edificios de los que tenemos constancia material que más se podrían acercar a esta tipología de Martyrium que rechaza Gregorio lo representa San Babilás en Kaoussié (cerca de Antioquía, Turquía) ${ }^{19}$, pero sobre todo el Martyrium de Siquem (cerca de Nablus, Cisjordania) ${ }^{20}$. Por el contrario, en el edificio de Nisa los

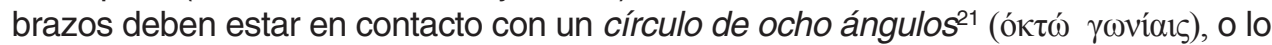
que es lo mismo y como seguidamente aclara Gregorio, un octógono (óktó $\gamma \omega v o v)$ ocupando el centro. Los cuatro brazos se unen a cuatro de los costados del octógono mediante arcos (uno por brazo), quedando así «libres» otros cuatro lados del octógono, que en lugar de salas rectangulares ${ }^{22}$ habrán de tener exedras o ábsides

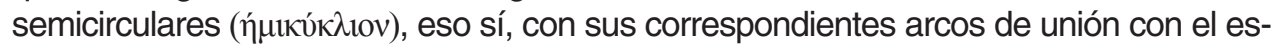
pacio central octogonal que, por consiguiente, tendrá tantos arcos como lados.

Gregorio define igualmente los detalles estructurales del interior del edificio, indicando que delante de cada pilar angular del octógono deberá haber una columna, que dichas columnas habrán de soportar un arco (ocho), y que estos arcos suponemos formados por dovelas - habrán de estar adosados a los ocho ya existentes, es decir, los conformados por la propia estructura. Sobre los ocho arcos y según las proporciones ( $\sigma \nu \mu \mu \varepsilon \tau \rho i ́ \alpha v)$ de las ventanas que deberán situarse sobre aquellos, el octógono se elevará cuatro $\operatorname{codos}^{23}$, es decir, que sobre las ventanas

\footnotetext{
${ }^{19}$ Construido a partir del 379, fecha que se inscribe en el arco cronológico de Epístola XXV (373-395), lo que nos hace pensar en la existencia de un «arquetipo» de martyrium extendido en el Mediterráneo oriental en el último cuarto del siglo IV. Para el Martyrium de San Babilás y las construcciones de planta centralizada relacionables con el mismo vid. Krautheimer 1992 (1ª ed. original 1965), pp. 88-91; Grabar, op. cit. pp. 152-158; Smith, 1950, pp. 109-110; Mango, op. cit., p. 91.

${ }^{20}$ Levantado en el lugar donde se hallaba el Pozo de Jacob y desde el cual Jesús habló a la Samaritana, en este caso los cuatro brazos formarían exactamente una cruz griega. Sin embargo, el edificio es conocido únicamente a través de la descripción de Arnulfo, peregrino del siglo VII, aventurándose su posible datación anterior al 380. Para el mismo vid. Krautheimer, op. cit., p. 86; Grabar, op. cit., pp. 155-156; Smith, op. cit., pp. 110-111. De los autores citados se desprende que el modelo arquitectónico de planta cruciforme, aun teniendo antecedentes en la arquitectura romana (no únicamente la funeraria), tiene un claro «prototipo cristiano" en la iglesia constantiniana de los Santos Apóstoles de Constantinopla.

${ }^{21}$ Teja, R., op. cit., p. 68, traduce «círculo ochavado».

22 De haber sido así, del octógono central partirían ocho brazos rectangulares, confiriendo al edificio un aspecto estrellado, no ajeno, sin embargo, a la morfología de algunos edificios martiriales conocidos como el supuesto Martyrium del Apóstol Felipe en Hierapolis (Frigia, actual Pamukkale, Turquía), datado hacia inicios del siglo V. Vid. Krautheimer, op. cit., pp. 188-190; Smith, op. cit., pp. 102-103, con bibliografía.

${ }^{23}$ Evidentemente la unidad de medida básica del edificio son los codos y (como se verá más adelante) los pies, cuya equivalencia en nuestro sistema métrico decimal no afecta a la propias proporciones $\left(\sigma 0 \mu \mu \varepsilon \tau \dot{\alpha}^{\alpha} \alpha v\right)$ por las que se rige el edificio. De todos modos, para hacernos una idea aproximada de las medidas que proporciona Gregorio, podemos señalar que el codo equivale, de manera muy aproximada, a unos $45 \mathrm{cms}$. Existen opiniones que hablan de unos 44,13 cms. (Keil, op. cit., p. 81), de 44,39 cm.
} 
habrá lo que podemos denominar un tambor, de la altura mencionada. Este refuerzo estructural de la zona central se relaciona con la cubierta que debe coronar el edificio y que, como se detalla, corresponde a una estructura que, partiendo de

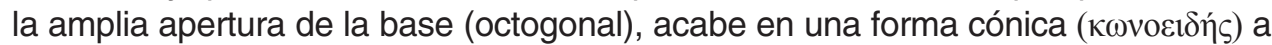
modo de cúpula ${ }^{24}$. Se trata del mismo tipo de cubierta que presentan edificios de la importancia de la rotonda de la Anástasis de Jerusalén de época constantiniana donde, como sabemos, viajó Gregorio-, así como una importante cantidad de precedentes arquitectónicos de la edilicia funeraria romana (mausolea), de los que derivan muchas de las fórmulas de los martyria cristianos ${ }^{25}$. Nos encontramos, por tanto, con una solución frecuente para la arquitectura de la época ${ }^{26}$.

Las siguientes instrucciones de Gregorio pasan a detallar las medidas y proporciones que han de observar las diversas partes del edificio, empezando por las dimensiones de las salas rectangulares, a saber, ocho codos de ancho (lo que nos proporciona la medida de los lados del octógono central, pudiendo calcular sus dimensiones y su área), por «algo más» de doce de largo ${ }^{27}$, y de altura la que re-

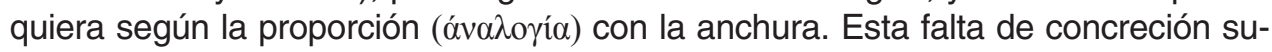
pone un problema para el cálculo exacto de buena parte de las dimensiones (y proporciones) restantes del edificio, suponiendo igualmente la presencia del factor críptico por el que Gregorio no precisa todas y cada una de las medidas necesarias, al dar por hecho que la inteligencia de su interlocutor lo hace innecesario ${ }^{28}$. Sobre esta misma cuestión habremos de volver más adelante, sin embargo cabe señalar que uno de los textos que resultan clave a la hora de establecer los cálculos para este mismo tipo de proporciones es el pasaje del De Civitate Dei de San Agustín (Lib. $\mathrm{XV}, \mathrm{XXVI}, 1)$, donde se explica la construcción del Arca de Noé, y las medidas que de la misma le proporcionó Dios (300 x 50 × 30 codos $)^{29}$.

(Arias Páramo, 1989, tabla de la p. 62), en cambio otras de 46,25 cm. (según se desprende del cálculo que de los 4 codos hace Maraval (op. cit., p. 292, n. 2).

${ }^{24}$ Tal y como confirma Smith, op. cit., pp. 31-32.

${ }^{25}$ Incide en este tema de un modo especial Grabar, op. cit., pp. 141 ss., pero de un modo concreto para la tipología en la que este autor incluye el Martyrium de Nisa, vid. las pp. 152-161. Por otra parte, para la influencia arquitectónica ejercida por la rotonda de la Anástasis en la arquitectura posterior vid. Krautheimer, 1942, pp. 1-33, espec. 2-20.

${ }^{26}$ Como queda perfectamente reflejado en el estudio citado de Smith, pp. 16 ss.

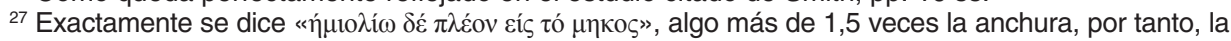
longitud de cada brazo habrá de ser «algo más» de doce codos.

${ }^{28}$ En efecto, según Gregorio esta falta no debe suponer un problema para Anfiloquio. Por otra parte, el tema del cripticismo en referencia a las medidas de los templos tiene un claro precedente bíblico en las medidas del Templo que David proporciona a Salomón (Paralip. 28, 19), así como en la tradición pitagórica, de gran influencia en la arquitectura como relación armónica de números. Para la influencia y repercusión del pitagorismo en la Antigüedad Tardía vid. O’Meara, 1989.

${ }^{29}$ Edición de la B.A.C. a cargo de Santamarta del Río y Fuertes Lanero, 1988, pp. 216-218. El Arca es presentada como símbolo de la Iglesia y de Jesucristo, siendo sus proporciones equivalentes a las del cuerpo humano (siendo el cuerpo más perfecto el de Jesucristo). San Agustín sin duda cristianiza una tradición anterior de la que tendríamos un claro ejemplo en Vitrubio (De architectura, Lib. 3, Cap. 1) que, a su vez, la tomaría de la tradición helenística precedente (para las ediciones de Vitrubio consultadas vid. Infra). En este sentido, nos parece interesante la afirmación que al respecto formula en su momento Godoy indicando que los preceptos que según San Agustín, Dios dio a Noé para la construcción del Arca, constituyen las reglas de proporciones que encontramos en las iglesias hispánicas de los siglos IV al VIII (op. cit., p. 48.) 
Teniendo en cuenta que Gregorio indica de manera explícita que la altura habrá de estar proporcionada con respecto a la anchura (queda por tanto fuera la longitud), podríamos partir, como hipótesis de trabajo, de la proporción de 5:3 (anchura:altura) para calcular la altura de los cuatro brazos, y por tanto: $8 / 1,6$ o 8/ $\varphi$, entendiendo por « $\varphi$ » la proporción áurea $(\sqrt{ } 5+1 / 2=1,618)^{30}$, teniendo siempre en cuenta que esta altura corresponderá únicamente a la de los muros, faltando la correspondiente a la cubierta abovedada que los mismos habrán de sustentar (vid. Infra).

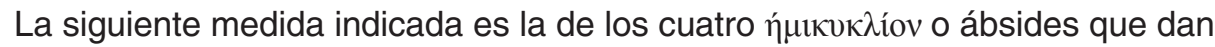
al espacio octogonal, cuya anchura (o mejor diámetro), como cabría esperar, es de 8 codos (han de coincidir lógicamente con la longitud de cada uno de los lados del octógono), con lo cual su perímetro será fruto, tal y como se dice en el texto, del trazado con un compás de un semicírculo, con la punta ubicada en el centro de cada uno los correspondientes lados del octógono y abierto hasta los extremos de los mismos. De este modo su profundidad o radio no es otra que 4 codos (la mitad del lado del octógono ${ }^{31}$. Respecto a la altura de dichos ábsides o exedras, nuevamente se nos pone en relación con la anchura (de nuevo 8), con lo cual podemos aplicar el mismo tipo de cálculo que se ha indicado al respecto de las naves (vid. supra) ${ }^{32}$. En lo concerniente a la cubierta de estos ocho espacios, no precisada en el texto, parece posible suponer que pudiera ser el cuarto de esfera (vid. Infra).

La última medida que proporciona Gregorio es la relativa al grosor de los muros, entendiendo que las que ha proporcionado hasta el momento corresponden siempre al espacio interior del edificio. Dicho grosor ha de ser en toda la construcción de 3 pies o, lo que es lo mismo, $2 \operatorname{codos}^{33}$.

Como se ha indicado, Gregorio asegura que Anfiloquio no tendrá problemas para el cálculo de la cantidad total de pies (cuadrados) del edificio, en base al grosor de los muros y las dimensiones del espacio interior, con el fin de poder conocer exactamente la envergadura de la obra y así enviar a Nisa el número correcto de obreros que son necesarios.

Una vez expresada de forma plena el contenido principal de la carta, el Padre niseno puntualiza que entre los obreros ha de haber quienes sepan construir

\footnotetext{
30 Vid. espec. Ghyka, 1968, vol 1, cap. III.

${ }^{31} \mathrm{Si}$ entendemos que cada lado del octógono actúa como diámetro de una circunferencia trazada con un compás, de la que a nosotros nos interesa únicamente su mitad, es obvio que el radio (o lo que es lo mismo, la profundidad de los ábsides) corresponde a la mitad del diámetro, es decir 4 codos.

${ }^{32}$ No hemos de confundir la anchura (8) con profundidad (4), por lo que la altura de dichas estructuras habría de ser, a nuestro entender, calculada tomando nuevamente el $8(8 / 1,6, \circ 8 / \varphi)$ como medida para el cálculo de las proporciones.

${ }^{33}$ Para la equivalencia entre codos-pies de 1 codo $=1,5$ pies, o si se prefiere 1 pie=0,6 periódico codos (cifra no excesivamente lejana al resultado obtenido de 1/ $\varphi$ ), vid. Keil, op. cit., p. 81; Arias Páramo, op. cit., p. 62.
} 
bóvedas ( $\left.\varepsilon^{\prime} \lambda \eta \sigma ı\right)$ sin estructura alguna de madera ${ }^{34}$, que son de mayor firmeza, siendo la madera además un material escaso en la región ${ }^{35}$.

Gregorio afirma su voluntad de emplear la piedra como materia básica para levantar el edificio, pero según él ésta presenta el problema de la lentitud en su talla y colocación, elevando así los costes de la construcción. Es en este punto cuando se aclara el salario que los obreros de Nisa pedían al obispo por su trabajo (más la comida): un sólido ( $\chi \rho v \sigma i ́ v \omega)$ de oro ${ }^{36}$, circunstancia que le obliga a plantearse el

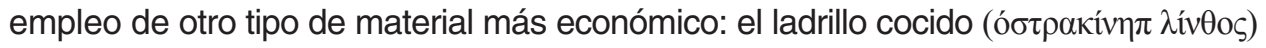

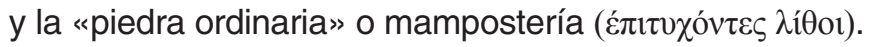

Gregorio nos deja ver los motivos por los que considera necesario pedir que los obreros vengan desde Iconium, a unos $170 \mathrm{Km}$. de distancia, con el esfuerzo añadido y suponemos coste que ello le pudiera acarrear: por una parte la mayor eficacia a la hora de realizar su trabajo, y por otra —probablemente de más peso- que su salario a percibir fuera inferior ${ }^{37}$.

La epístola prosigue detallando algunos de los elementos que han de componer la decoración arquitectónica del martyrium, lógicamente en piedra (mármol como se detalla más adelante) y que han de implicar el trabajo de canteros ( $\lambda \alpha 0$ óóos), a saber: las ocho columnas del octógono central (elementos «embellecedores» no carentes de una importante función estructural), con sus correspondientes basas, en forma de altar ${ }^{38}$, y sus capiteles en estilo corintio. No se especifican las dimensiones de dichas columnas que, hemos de suponer, deberán guardar relación con la altura del octógono hasta el nivel de arranque de los arcos que separan los espacios adyacentes del octógono central (cuatro naves y cuatro

34 Teja traduce «cimbras» (op. cit., p. 68) y Maraval «charpentre» (op. cit., p. 295). Este último puntualiza, acertadamente, que Gregorio no se refiere a las armaduras de madera de carácter provisional usadas para construir arcos, bóvedas, etc. (es decir «cimbras»), sino a las armaduras de madera de carácter fijo que, sustentando un tejado a dos aguas, forman el esqueleto de la propia cubierta.

${ }^{35}$ Ciertamente, la Capadocia se caracteriza por la escasez de madera. Para cuestiones de esta índole en la región de Capadocia y su reflejo en los textos de los Padres capadocios del siglo IV vid. Teja, 1974, espec. pp. 23-29.

${ }^{36}$ Podría desprenderse de las palabras de Gregorio que el salario de un sólido de oro corresponde a la cantidad que el obispo ha de desembolsar en un periodo concreto de tiempo (un día), independientemente del número de trabajadores implicados en la obra. En este sentido Mango (op. cit., p. 26) habla de 1 sólido diario para 30 obreros, con lo que la cantidad diaria recibida por cada uno de ellos ascendería a 1/30 de sólido, cifra que al propio Mango le parece desorbitante, puesto que supondría unos 10 solidi anuales para cada obrero, cuando lo normal serían de 5 a 7 piezas de oro. Para las cuestiones relacionadas con la economía de Capadocia en el s. IV, según el testimonio de sus Padres vid. Teja, op. cit., 1974, espec. pp. 159 ss. y Teja, op. cit. 1991, pp. 66-67, con bibliografía.

${ }^{37}$ No podemos comprobar la veracidad de las palabras de Gregorio en lo concerniente al prestigio de los obreros de Iconium a falta de testimonios arqueológicos relevantes pertenecientes a este momento en la actual Konya. Sí contamos con información al respecto de los operarios de la vecina Isauria, vid. Maraval, op. cit., p. 297, n. 4; Mango, 1966, pp. 358-365.

${ }^{38}$ Por «forma de altar» se ha querido entender que las basas han de tener forma de paralelepípedo, así Maraval (op. cit., p. 295, n.5, en base a Birnbaum, 1913, p. 206), añadiendo que Gregorio no alude a

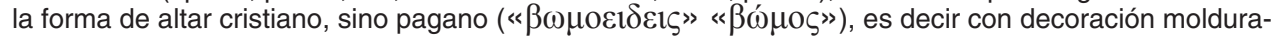
da a base de toros y escocias. En tal caso, el aspecto de las basas del martyrium de Nisa sería el habitual (circulares y molduradas) de la arquitectura del momento. 
ábsides). Por otra parte, las proporciones de las propias columnas (altura del capitel y de la basa con respecto al diámetro del fuste), podrían corresponder a las propias del orden corintio, por tanto, la altura del capitel (incluido el ábaco) debería equivaler al diámetro del fuste de la columna en su extremo inferior, y la altura de la basa (con todas sus molduras) ha de corresponder a 0'5 veces el diámetro del fuste en la misma zona ${ }^{39}$.

Se informa también que deberá ser igualmente competencia de los canteros obrar la puerta de acceso al edificio en mármol ( $\mu \alpha \rho \mu \alpha ́ \rho \omega v)$ y su correspondiente frontón triangular, con las decoraciones habituales a lo largo de las molduras. No podemos llegar a saber con exactitud lo que Gregorio entendía por habitual con respecto a dicha decoración, sin embargo podemos imaginar la presencia de una serie de molduras corridas que discurrirían tanto por las jambas como por el dintel de la puerta. Respecto a los motivos que podrían decorar dichas molduras, se ha indicado que pudieron incluir motivos de carácter zoomórfico ${ }^{40}$, sin embargo, es más probable que existiera un claro predominio de las formas vegetales estilizadas, combinadas o no con motivos geométricos (gotas, ovas, etc.) ${ }^{41}$.

El último elemento del que se han de hacer cargo los canteros es un peristilo ( $\pi \varepsilon \rho i ́ \sigma \tau \omega o v)$, del que Gregorio hasta el momento no había aportado datos, y del que dice que no ha de tener menos de 40 columnas, lo cual representa sin duda una cifra muy considerable teniendo en cuenta el carácter general del edificio ${ }^{42}$. Respecto a la ubicación del mismo, se ha planteado tradicionalmente que se pudo situar alrededor de martyrium, formando un cuadripórtico ${ }^{43}$, sin que, sin embargo, podamos descartar plenamente la posibilidad de que se articulara con el martyrium a modo de atrium, es decir, en uno de sus lados y en conexión con él, o antecediendo su acceso principal ${ }^{44}$. La fórmula del atrium como pieza porticada con funciones de representación del poder (en nuestro caso episcopal) ha sido bien identificada en mu-

${ }^{39}$ Así lo expresa Vitrubio de un modo específico en lo concerniente al capitel corintio (Lib. IV, Cap. 4), donde también advierte que para las basas las medidas son las mismas que las del orden jónico (por tanto las que aparecen en III, 5). Las ediciones de Vitrubio consultadas son las españolas de Olivier (1995) y Blánquez (1995), así como la francesa de Gros (ed. 1969) y la inglesa de Granger, (ed. 1983, vol II.).

${ }^{40}$ Así parece insinuarlo Maraval (op. cit., p. 298, n. I).

${ }^{41}$ Al modo de ejemplos como el entablamento de la basílica de Santa Sofía de Constantinopla de época de Teodosio II de inicios del siglo V (ca. 404-415). Vid. Krautheimer, op. cit. 1992, p. 123, fig. 53. Aparecen también representaciones de este tipo de elementos en las artes plásticas del momento, así la hoja del díptico Trivulcio (actualmente en el Castello Sforzesco de Milán), datada hacia el 400, en cuya mitad inferior aparece representada la puerta principal del Santo Sepulcro, vid. Compostella, 1990, con bibliografía.

42 Llama la atención que Gregorio no haya dicho nada de esta estructura hasta el momento, sobre todo ante el hecho del coste adicional que la misma supone. Asimismo, sorprende también que no proporcione medida alguna del mismo, mencionando simplemente el número de columnas. En el apartado siguiente habremos de volver sobre la problemática del peristilo, abordando la cuestión de sus medidas, etc.

${ }^{43}$ Así lo hacen Keil, op. cit., fig. 62; Grabar, op. cit., p. 613, fig. 82; Smith, op. cit., fig. 27; Mango, op. cit., p. 26, fig. 24, entre otros, siendo el punto de partida de todos ellos la planta propuesta por Keil en 1903.

${ }^{44}$ Así, por ejemplo, en el complejo de la Iglesia de la Natividad de Belén de época constantiniana, donde un espacio cuatriporticado de 30 columnas antecede el acceso este a la basílica de tres naves, que a su vez conecta con el edificio octagonal (Martyrium) situado sobre la gruta de la Natividad. Para dicho edificio, vid. Krautheimer, op. cit. 1992, pp. 67-69 y fig. 26 (reconstrucción isométrica de su aspecto hacia el 333); Smith, op. cit., pp. 101-102, con bibliografía. 
chas regiones del Mediterráneo en época tardoantigua (incluida la Hispania del siglo VII gracias a casos como Mérida ${ }^{45}$ ), existiendo claros ejemplos en oriente como el Peristilhof adyacente al costado norte de Basílica de la Santa Cruz en Sergiópolis (Rusafa, Siria) ${ }^{46}$, o en el espacio porticado existente entre el Martyrium y la Anástasis en el complejo del Santo Sepulcro de Jerusalén ${ }^{47}$.

Gregorio añade que, si bien, él habrá de proporcionar los materiales para la decoración, habrá de ser la $\tau \varepsilon ́ \chi v \eta$ de los talladores de la piedra la que dé forma a la materia $^{48}$.

La epístola finaliza dándonos detalles sobre el tipo de contratos que Gregorio quiere establecer con los obreros, es decir, el grado de detalle que los mismos han de tener con respecto a la actividad exacta que cada hombre ha de realizar diariamente. El motivo no es otro que evitar el fraude por parte de los obreros que, reclamando su paga, no hayan realizado el trabajo asignado. Estas líneas suponen un testimonio de gran valor con respecto del tipo de contratación propio de la época (al menos en Capadocia), puesto que lejos de constituir un ejemplo particular, propio de las preocupaciones de un obispo concreto, Gregorio generaliza al hablar de la mezquindad que le supone al resto de la gente el que se detallen tanto los contratos ${ }^{49}$. Además, se especifica que ha de ser el propio Anfiloquio quien establezca los contratos con los obreros, siendo el factor principal para convencerlos de que acepten la oferta de trabajo, la garantía del pago completo de lo estipulado. Llama por último la atención el hecho de que no se establezca una jerarquía dentro de los trabajadores a contratar, men-

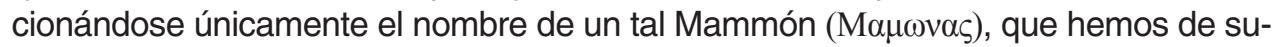
poner jefe o capataz de una cuadrilla de obreros. Parece lógico suponer que, según se desprende del propio texto de la epístola, es el obispo quien proyecta el edificio sin mención alguna de la intervención de un «arquitecto» o similar ${ }^{50}$.

45 Vid., Godoy-Tusset, 1994.

${ }^{46}$ Ibid., en base a los resultados de Ulbert, T., Resafa II. Die Basilika des Heiligen Kreuzes in ResafaSergiupolis, 1986, Mainz am Rhein, donde el autor denomina a este espacio Peristilhof, término más cercano al griego $\pi \varepsilon \rho i ́ \sigma \tau \omega o v$ que aparece en nuestra epístola. Dicha estructura se ubica como hemos indicado, al norte de la basílica principal, en conexión directa con ella, estando esta última también en conexión con un martyrium al sudeste.

47 Vid. supra, en base al testimonio de la peregrina Egeria de los años 381-386. Para el texto de Egeria vid. la edición Janeras, 1986.

${ }^{48}$ Esta interesante concepción de la transformación de la materia muestra un trasfondo de raíz platónica, pasada por el tamiz plotiniano La misma aparece claramente expresada en la Enéada V, 8, 1 de Plotino (vid., la ed. inglesa de Armstrong, 1984, pp. 236-241 y española de Mínguez, 1967, pp. 158160 ), cuando se compara dos piedras, una en estado natural (sin trabajar) y la otra tocada por la $\tau \dot{\varepsilon} \chi V \eta$, entendiendo que la segunda - en este caso correspondiente a una escultura de bulto redondo- ha adquirido una belleza ( $\kappa \alpha ́ \lambda \lambda o \varsigma)$, de la que la primera piedra carece, belleza que ha sido introducida en ella a través de la $\tau \varepsilon ́ \chi \vee \eta$. Para la influencia del pensamiento platónico en los Padres de la iglesia y especialmente en Gregorio de Nisa vid. el trabajo de Ivánka, 1992, pp. 115-142.

${ }^{49}$ Para este tipo de cuestiones de índole social y económica vid. Teja, op. cit. 1974, passim, espec. pp. 67-79.

${ }^{50}$ Al respecto vid. Mango (op. cit., 1975, p. 24), indicando la existencia de dos categorías bien diferenciadas, por una parte el mêchanikos o mêchanopoios, de mayor prestigio y con conocimientos de matemáticas e ingeniería, y por otra, el architectôn, de rango muy inferior, más versado en la praxis que en cálculos matemáticos, que correspondería a un maestro constructor o albañil jefe. 


\section{PROPUESTA DE RESTITUCIÓN DEL EDIFICIO}

A partir de la información que proporciona Gregorio de Nisa en su epístola, la restitución en planta del edificio no supone una tarea en exceso difícil, gracias a contar con buena parte de las medidas necesarias, a excepción de la longitud de las naves («algo más de 12 codos») y la ubicación exacta del peristilo. Menos sencilla se presenta en cambio la restitución volumétrica, puesto que carecemos de medidas expresadas de un modo preciso, a excepción de la altura del tambor de la cubierta del octógono (4 codos). El elemento esencial para calcular dicha altura es el de su proporción con respecto a la anchura y, por consiguiente, al criterio que utilicemos para realizar el cálculo de dicha proporción.
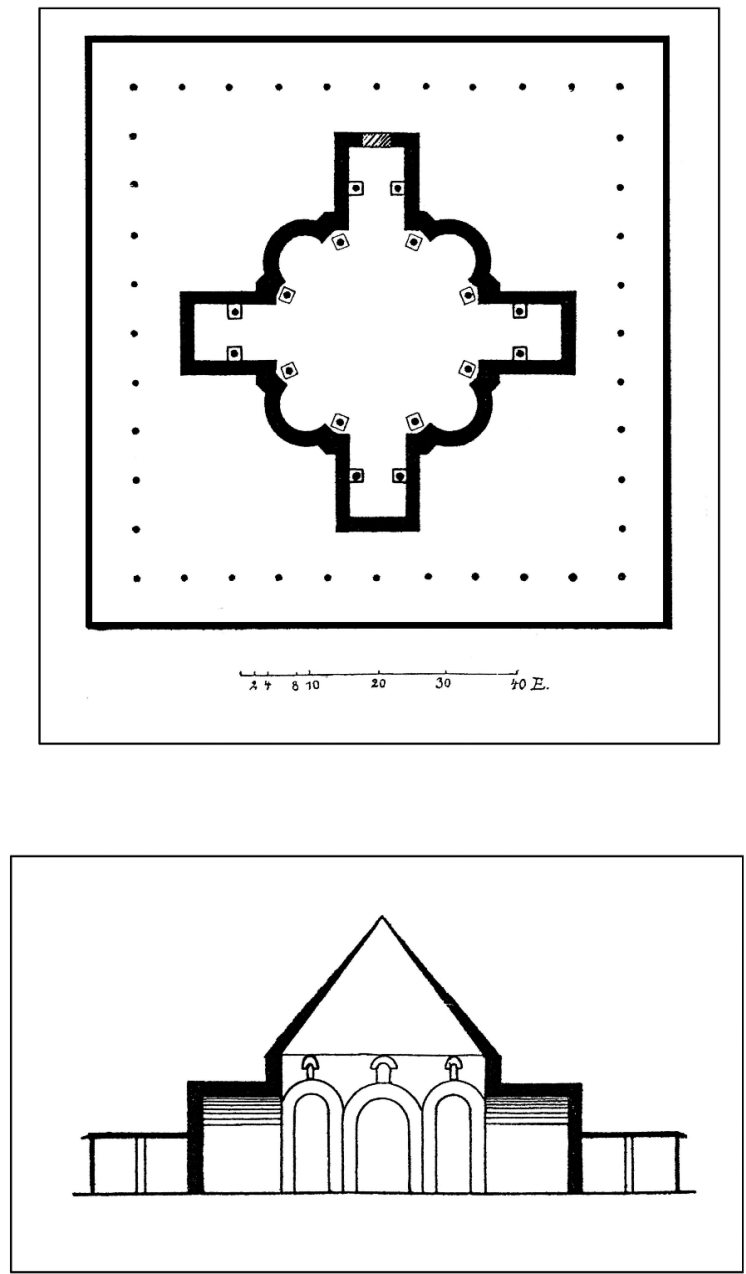

2. Propuesta de restitución de la planta y alzado (sección transversal) del Martyrium de Nisa, según B. Keil (1903, figs. 62 y 63 respectivamente). 
Hasta el momento, uno de los estudios más destacados para la restitución de la planta del martyrium de Nisa ha sido, sin duda, el publicado por Keil hace más de un siglo, en 1903 (fig. 2) ${ }^{51}$. En su planta observamos, sin embargo, una solución discutible al situar una pareja de columnas adosadas a los muros de cada uno de los brazos rectangulares, más o menos en su mitad, elemento que no aparece mencionado en el texto. Dicha solución ya no aparecerá en la posterior y no menos influyente restitución que publicará décadas más tarde Maraval (fig. 3), restitución en la que, sin embargo, la escala utilizada viene expresada en metros en lugar de $\operatorname{codos}^{52}$.

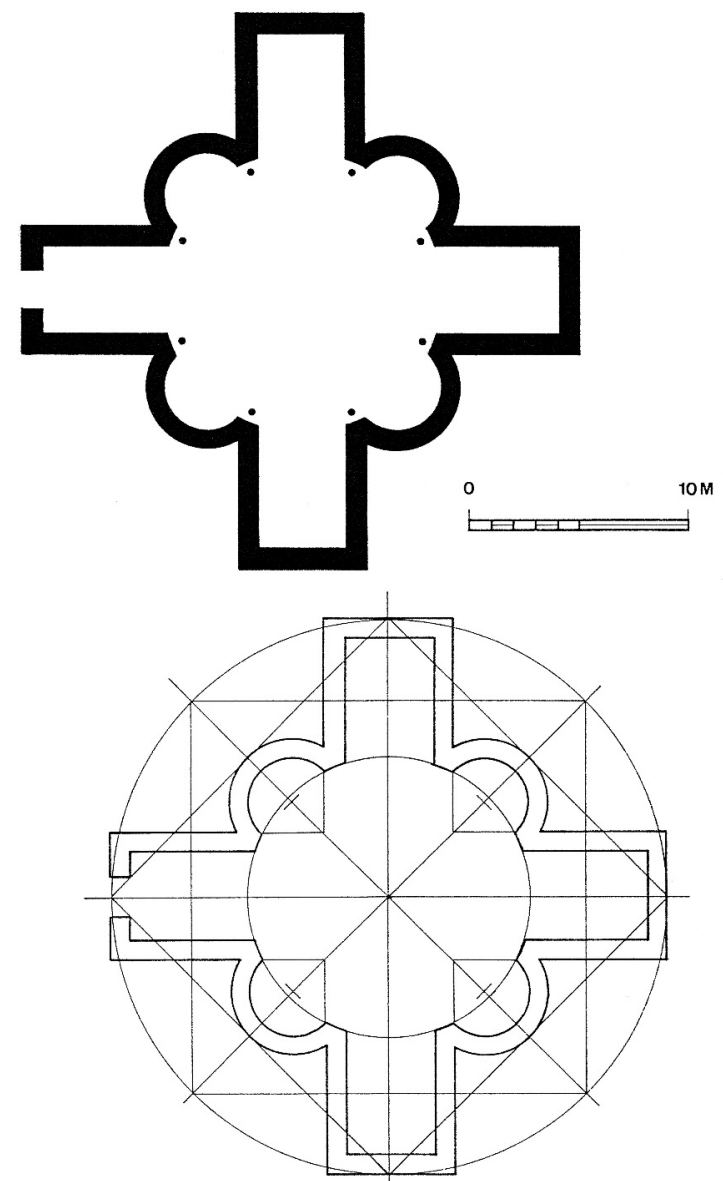

3. Propuesta de restitución de la planta del edificio, según P. Maraval (de: Teja, 1991, fig. 1) y valoración de sus relaciones geométricas, según L. Tera (de: Teja, 1991, fig. 2).

51 Vid, Keil, op. cit.

52 Vid. Maraval, op. cit. (al final de la obra). Dicha planta es la que utilizará Teja, op. cit., 1991, p. 64, fig. 1, acompañándola de una propuesta de las relaciones geométricas de la misma (p. 65, fig. 2) a cargo de L. Tera. La misma planta de Maraval, será también la empleada en el posterior estudio de Silvas, op. cit, p. 197. 
Siguiendo el texto de Gregorio, para efectuar un intento de restitución la planta del edificio, debemos tener en consideración esencialmente las cifras 12, 8 y 4 , entendiendo por 12 la longitud provisional de las naves (exactamente «algo más de 12", sin que por el momento sepamos cuanto más), 8 para la anchura de los brazos, los lados del octógono y el diámetro de los ábsides, y 4 para el radio de éstos últimos (fig. 4).

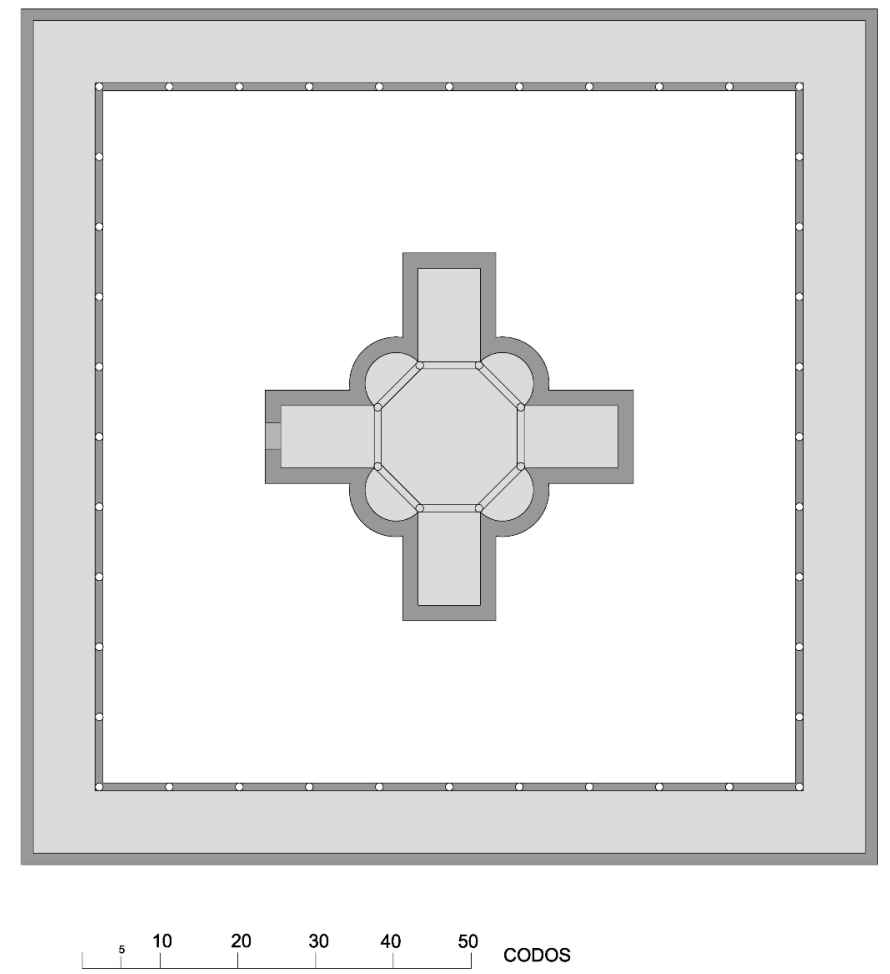

4. Propuesta de restitución de la planta: Edificio central y peristilo, según S. Vidal.

Centrándonos en primer lugar en el octógono central, calcularemos su diámetro, anchura ${ }^{53}$ y área. Para el cálculo ${ }^{54}$ del diámetro hemos de tomar una octava parte del octógono y dividirla en dos partes iguales (generando por tanto dos triángulos rectángulos), correspondiendo la recta que separa estas dos partes a la

${ }^{53}$ Como sabemos, tratando un polígono regular como es el octógono, el diámetro no es equivalente a la anchura, puesto que el primero va de un vértice a su correspondiente vértice opuesto, mientras que la anchura va de la mitad de un costado a la mitad de su costado opuesto.

${ }^{54}$ Todos los cálculos, así como la terminología expresada en los mismos, se basan en sencillos principios de geometría conocidos en la Antigüedad y que pueden hallarse en infinidad de obras generales y diccionarios de matemáticas. Para una visión histórica de cada uno de los principios que tratamos es de consulta esencial, dado su enfoque cronológico, Collette, 1985 (espec. capítulos 4 al 6 y 9). Para un planteamiento del tema desde un enfoque conceptual en lugar de cronológico, vid. Bell, 1949, esp. pp. 69-79. 
llamada apotema (fig. 5). Tomando una de las mitades (un triángulo rectángulo), tendremos que el cateto menor o cateto opuesto, es exactamente la mitad del costado del octógono (4 codos), que la apotema es el cateto mayor o contiguo, y que la hipotenusa nos da la medida del radio del octógono. No conocemos todavía el valor de la apotema, pero sí el ángulo de nuestro triángulo $\left(22,5^{\circ}\right)$, con lo cual podemos conocer el valor de su hipotenusa ${ }^{55} \mathrm{y}$, por tanto, del radio del octógono, que es 10,45 y, por consiguiente el diámetro, que lógicamente corresponde al doble, es de 20,9 codos. Respecto a la anchura, es ahora fácil de calcular, puesto que corresponde al doble de la apotema. Ya se ha dicho que la apotema es el cateto mayor del triángulo que hemos tomado (triángulo que equivale a 1/16 parte del octógono), y del que ya conocemos cateto menor (4) e hipotenusa $(10,45)$, por tanto aplicando el teorema de Pitágoras podremos hallar el valor del cateto mayor (en nuestro caso la apotema) ${ }^{56}$. El resultado es 9,65 , lo que multiplicado por dos nos da

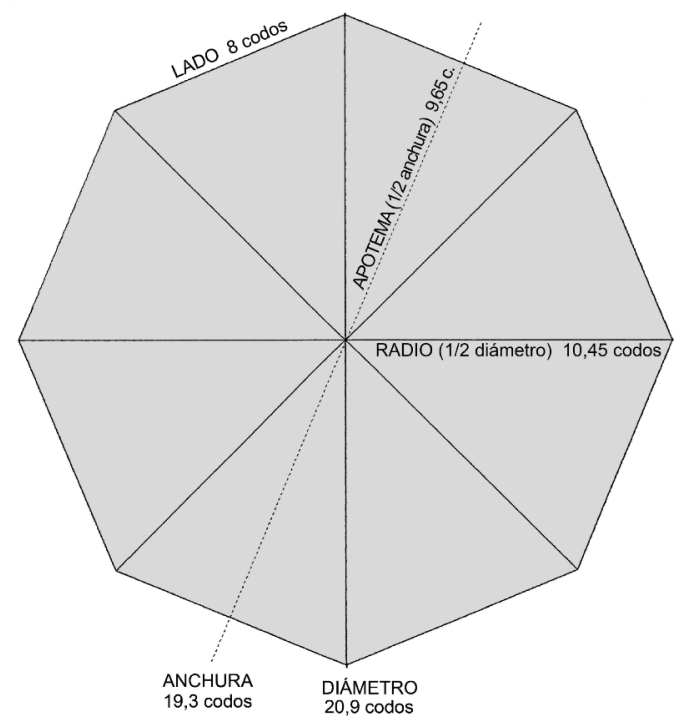

5. Esquema de las principales medidas del octógono central, en planta, según S. Vidal.

\footnotetext{
55 El ángulo del triángulo es 22,5 grados puesto que corresponde a 1/16 parte del total del octógono, o lo que es lo mismo 1/16 parte de 360 grados. Al conocer el ángulo y el cateto menor, la fórmula para calcular la hipotenusa es la siguiente: seno del ángulo (sen. de 22,5) =4/hipotenusa, o lo que es lo mismo: $h=4 /$ sen. 22,5. Por tanto $h=4 / 0,38268$, lo que da: $h=10,45$. Debe puntualizarse que en la Antigüedad no se empleaban las razones trigonométricas tal y como las conocemos hoy en día (senos y cosenos), sin embargo, se obtenían los mismos resultados mediante el uso de cuerdas, siendo la equivalencia respecto a nuestro sistema actual: sen. $A=$ cuerda 2A / 120. Para esta cuestión vid. Collette, op. cit., pp. 141-147 y 152-154, espec. p. 153, donde se pone de relieve la importancia en la Antigüedad, para las cuestiones de carácter trigonométrico, del libro I del Almagesto de Tolomeo (Ca. 85-165 d. C.), cuyos conocimientos no perderán vigencia hasta finales de la Edad Media.

${ }^{56}$ Como sabemos $h^{2}=c 1^{2}+c 2^{2}$, en nuestro caso $10,45^{2}=4^{2}+c 2^{2}$, es decir $109,2025=16+c 2^{2}$, lo cual equivale a $109,2025-16=c 2^{2}$, por tanto $93,2025=c 2^{2}$, con lo cual la raíz cuadrada de 93,2025 corresponderá al c2, es decir 9,65.
} 
19,3, es decir, la medida correspondiente a la anchura del octógono del edificio. Por último, podemos obtener el área del octógono de la multiplicación del perímetro (que en nuestro caso es de $8 \times 8$ ) por la apotema $(9,65)$, dividido entre dos, es decir, 64 × 9,65/2, lo que equivale a 308,8 codos cuadrados.

Para los absidiolos conocemos tanto su diámetro como su radio (8 y 4 respectivamente), por tanto su área es de 25,13 codos cuadrados ${ }^{57}$.

Respecto a las naves, conocemos su anchura (8 codos) y su longitud (algo más de 12 codos), lo cual nos daría un área no inferior a los 96 codos cuadrados. Sin dejar estos cuatro espacios y antes de calcular su posible altura, estamos en condi-

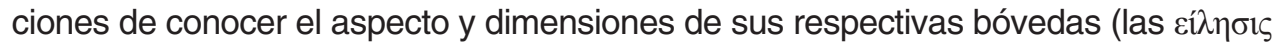
que, como indica el texto, han de ser de obra, sin empleo de armaduras de madera), cuyo perfil ha de ser semicircular y, por tanto, su cubierta corresponder a una bóveda de cañón. Si tenemos en cuenta que la anchura de la imposta (diámetro) es de 8 codos, lógicamente el radio de las bóvedas es de 4, y por tanto el arco que las genera es igual al que (en planta) presentan los absidiolos del espacio central58. El volumen de dichas bóvedas (contando una longitud de 12 codos) es de 150,79 codos cúbicos, lo cual equivale al área de los propios semicírculos multiplicada por $6^{59}$.

Volviendo a los ábsides del octógono central, el volumen de sus cubiertas (1/4 de esfera) sería 50,26 codos cúbicos o, lo que es lo mismo, el resultado de multiplicar por 2 el área de los semicírculos de la planta ${ }^{60}$.

Nos faltaría ahora conocer la anchura total del edificio, hallándola de la suma de la longitud de las naves multiplicada por dos (24), y la anchura del octógono $(19,3)$, es decir 43,3 codos, a los que habríamos de sumar los 6 pies del grosor de los muros ( 3 por cada lado), es decir 4 codos, obteniendo el total de 47,3 codos.

Estamos pues en condiciones de intentar hallar la longitud exacta de las naves, mediante la multiplicación de «algo más» de 1,5 veces la anchura, lo cual significa algo más de 12 codos (pero menos de 13). Para ello emplearemos el método de cálculo basado en la sección áurea $(1,618$, es decir «algo más» de $1,5)$, multiplicándola por la anchura, lo que arroja una cifra de 12,944 codos de longitud. El método que acabamos de aplicar, en su forma simplificada, tiene tras de sí un razonamiento geométrico (en su momento sabiamente aplicado por $\mathrm{R}$. Trinci), basado en el trazado de un triángulo rectángulo a partir del cual, mediante el trazado de circunferencias tangentes, puede hallarse la sección áurea con total exactitud ${ }^{61}$. Por consiguiente, si la medida de las naves es de 12,944 x

\footnotetext{
${ }^{57}$ Area del círculo $\left(\pi \cdot r^{2}\right)$, dividida entre 2 .

${ }^{58}$ Correspondencia que ya fue observada por Keil (op. cit., p. 82).

${ }^{59}$ La fórmula sería $2 \pi$ · radio · longitud, dividido entre 2 , siendo el radio 4 y la longitud 12.

60 De todos modos, la fórmula para hallar dicha área seria la de la esfera $\left(4 \pi \cdot r^{2}\right)$, dividida entre 4.

61 Vid. Trinci, 1984, pp. 475-540, espec. pp. 484-485, figs. 1-2. Como podemos apreciar, la longitud propuesta para las naves de 12,9, se acerca en gran medida a los «rectángulos armónicos» de proporción 13:8, basados en la proporción áurea, vid. Ghika, op. cit., lám. XXV.
} 
8 , su área es de 103,55 codos cuadrados, el volumen de sus cubiertas de 162,659 codos cúbicos, y la anchura total del edificio de 45,188 codos, más los cuatro codos (2 por cada extremo) de los muros de cierre, es decir: 49,188.

En referencia a la restitución volumétrica del edificio (fig. 6), se indicó más arriba la posibilidad de emplear la proporción 5:3, anchura:altura, como base del

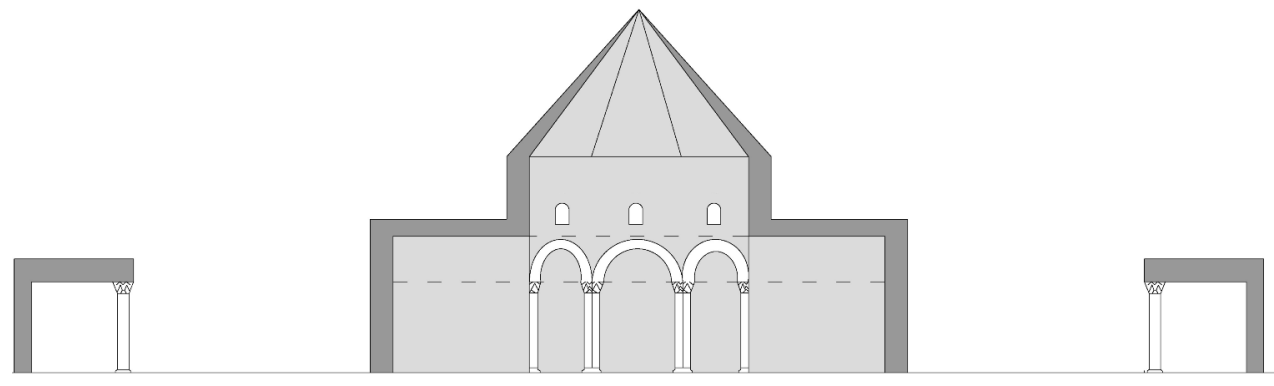

\begin{tabular}{ccccccc}
5 & 10 & 20 & 30 & 40 & 50 & coDOS \\
\hline & 1 & 1 & 1 &
\end{tabular}

6. Propuesta de restitución del alzado, sección transversal, según S. Vidal.

cálculo de la altura de los cuatro brazos (las proporciones del Arca de Noé y del Cuerpo de Cristo), teniendo en cuenta que a esta altura le faltaría la de las bóvedas, que ahora ya conocemos. Dicho cálculo nos daría, sin embargo, una altura para las naves excesivamente baja ${ }^{62}$.

Hemos de tener presente que Gregorio señala que la altura habrá de hallarse en proporción a la anchura, pero la aplicación estricta de la proporción 5:3 resulta a todas luces insatisfactoria. No podemos, sin embargo, desligarnos por completo de las medidas del cuerpo humano (como se ha dicho, ejemplificado en las medidas del más perfecto, el de Cristo), al estar el hombre creado por Dios a su imagen y semejanza ${ }^{63}$. Teniendo en cuenta que las proporciones que rigen a las medidas

\footnotetext{
${ }^{62}$ Si la anchura es 8, aplicando la proporción 5:3 la altura sería únicamente de 4,8 codos. Por otra parte, para el estudio de las proporciones existentes en obras conservadas como Santa Sofía, algunas basílicas de los Balcanes y su comparación con las de la arquitectura precedente (por ejemplo el templo de Zeus en Olimpia), vid. Junecke, 1983. También son interesantes los capítulos que se dedica al tema en Ghyka, op. cit., pp. 81-144, así como Trinci, op. cit. para las basílicas de San Vital de Rávena y San Apolinar en Classe, Los sistemas de proporciones de la Antigüedad de base pitagórica siguen siendo conocidos y empleados en la arquitectura altomedieval tal y como demuestra Arias Páramo, op. cit., para la arquitectura prerrománica asturiana.

${ }_{63}$ Para esta cuestión y su repercusión en la arquitectura vid. Donceel-Voûte, 1988; Smith, op. cit:; Godoy, op. cit., p. 47, donde se alude a la cuestión del templo cristiano entendido como auténtico microcosmos.
} 
de nuestro edificio deberían estar, al menos en parte, en consonancia con las del cuerpo humano y recordando que el propio Gregorio fue autor de un tratado Sobre la creación del hombre (vid. supra), se observa como la planta del edificio se inscribe tanto en un cuadrado como en un círculo (fig. 3) ${ }^{64}$; ello responde a la noción bien conocida por Gregorio del hombre como microcosmos, que queda visualizada en el no menos conocido esquema vitrubiano del homo ad quadratum, homo ad circulum $^{65}$. Es sabido que la relación proporcional de carácter numérico entre las diferentes partes del cuerpo humano, en que se fundamenta el esquema vitrubiano, no era desconocido en la Antigüedad Tardía, apareciendo además de en Gregorio tanto en San Agustín (vid. supra), como muy posteriormente en manuscritos del siglo XII ${ }^{66}$ o inclusive, en ejemplos de la pintura altomedieval hispánica ${ }^{67}$, sin olvidar sus posibles conexiones con ciertos pasajes bíblicos ${ }^{68}$. De hecho, Vitrubio toma el esquema de una riquísima tradición anterior, de raíz pitagórica, cuyos exponentes irían desde Pitágoras y sus discípulos inmediatos ${ }^{69}$, al propio Platón ${ }^{70}$, Filolao o Nicómaco de Gerasa, entre otros ${ }^{71}$.

Aceptando este parámetro de proporciones, la anchura y altura de las naves habrían de formar en sección un cuadrado perfecto de 8 × 8 codos. Cuadrado que, lógicamente, generaría un espacio de forma paralelepípeda correspon-

\footnotetext{
${ }^{64}$ Para este tipo de relaciones geométricas vid. Teja, op. cit., p. 65 fig. 2 (según L. Tera).

${ }^{65}$ Vitrubio, lib. III, cap. I. Para las ediciones de Vitrubio vid. supra. Por otra parte, ha de tenerse en cuenta que dicha noción era bien conocida por Gregorio, al señalar en sus escritos que el hombre es un microcosmos en el que se refleja toda la armonía y la proporción del Universo, puesto que está hecho a imagen y semejanza del Creador (Gregorio, In Psalmos, cap. III: Migne, PG 44, cols. 437-444; Gregorio, De hominis opificio, caps. V, XVI: Migne, PG 44, cols. 127-128, 177-188). Para esta cuestión y la amplia bibliografía existente al respecto vid. especialmente Quasten, op. cit., pp. 306-307.

${ }^{66}$ Entre otros, el Códice latino de Santa Hildegarda, de la Biblioteca estatal de Lucca, en el que el hombre aparece como centro de la Creación, inscrito en un círculo y con los brazos extendidos o, en otro sentido, el mapamundi del Manuscrito de Ebstorf (1284), donde el cuerpo de Cristo corresponde al propio mapamundi, con su cabeza ubicada en el Edén y el ombligo en Jerusalén, vid. Donceel-Voûte, op. cit., pp. 486-487, con bibliografía.

${ }^{67}$ Así, el llamado «orante» del ábside de la iglesia de Sant Quirze de Pedret (Barcelona), hoy en el Museu Diocesà y Comarcal de Solsona (Lleida), datado en el siglo IX, donde la figura de Cristo aparece con los brazos extendidos, dentro de un círculo, sobre el cual hay un ave fénix como símbolo de resurrección, vid. Barral, 1981, pp. 127-129.

${ }^{68}$ Así, el tema de las proporciones en arquitectura (expresadas en codos, es decir, con medidas ajustadas a las proporciones humanas) aparece de un modo especial en Ezequiel, 40-42 (revelación del nuevo Templo, cuyo perímetro externo total es de 500 x 500 codos), aunque también son importantes las menciones al respecto del Santuario de Moisés (Ex., 25-27, con un perímetro de 100 x 50 codos), o incluso la Jerusalén celeste del Apocalipsis (Ap. 21, cuyas medidas de altura, anchura y profundidad son idénticas: 4.440.000 codos), además de la ya mencionada Arca de Noé (Gen. 6, 15, de 300 x 50 x 30 codos).

${ }^{69}$ Cuyos postulados en este sentido son conocidos esencialmente gracias a Filolao, Euclides, Nicómaco de Gerasa y Jámblico, vid. Kirk-Raven-Schofield, 1994, espec. textos 277 a 280; Parra León, 1966; Collette, op. cit., pp. 64-92; Bell, op. cit., pp. 69-79; Ghyka, op. cit., n, pp. 1-38.

${ }^{70}$ De un modo implícito en el Timeo, al decir que el hombre está hecho a imitación del Todo, el cual es «forma esférica y circular, siendo las distancias exactamente iguales, desde el centro hasta los extremos», además, Platón señala que la parte del cuerpo que más se acerca por su forma al Todo y, por tanto, la más perfecta, es la cabeza. Para el Timeo vid. la edición de Mínguez, 1990, pp. 1103-1179, espec. pp. 1136 y 1144, con traducción y preámbulo a cargo de F. de P. Samaranch.

${ }^{71}$ Para esta cuestión en Filolao vid. Burnes, 1986, pp. 378-396; Kirk-Raven-Schofield, op. cit., espec. textos 424 y 429. Respecto a Nicómaco de Gerasa cuya obra clave en este sentido es su Theologumena Arithmeticae, vid. D’Ooge-Robbins-Karpinski, 1926.
} 
diente a las naves, de 12,944 x 8 × 8 (por tanto con un volumen de 828,416 codos cúbicos), que se vería coronado por su correspondiente bóveda de cañón de 12 x 4 (vid. supra). Del mismo modo, la altura de los absidiolos del octógono sería también 8 , siendo como sabemos su radio de 4 y por tanto su volumen de 100,53 codos cúbicos (4 veces el área del semicírculo) ${ }^{72}$, a los que se les ha de sumar los 50,26 codos cúbicos de su cubierta (114 de esfera).

Faltaría por calcular la altura del octógono central que, como recordaremos, ha de tener, además de los 8 codos a los que se situaría la línea de imposta de sus arcos, los 4 codos del radio de los mismos arcos (de medio punto); a continuación tendríamos las ventanas, el tambor de 4 codos y, finalmente, la cubierta conoidal, una pirámide de 8 caras.

En primer lugar, el octógono incluyendo el tambor mediría 16 codos de altura. A ello hemos de añadir la altura de las ventanas para lo cual, si consideramos que al igual que en las naves la altura debe estar proporcionada con la anchura, debemos obtener un total de 19,3 codos. De este modo, 3'3 codos (19'3 menos 16) corresponderían a la altura de las ventanas. En este caso, el volumen del octógono (perímetro x apotema / 2 altura) sería de 5959,84 codos cúbicos.

Existe, sin embargo otra posibilidad, por la que en lugar de tomar la anchura del octógono, se podría tomar su diámetro (20,9 codos), resultando en tal caso una altura para las ventanas considerablemente superior, de 4,9 codos.

Para la cubierta del octógono, contamos únicamente con la medida de su base: el propio octógono de la planta, de 8 lados de ocho codos cada uno, es decir, un perímetro de 64 codos. El cálculo depende, por tanto, exclusivamente del grado de inclinación que podamos considerar oportuno para la estructura que, en todo caso, habrá de tener una forma de pirámide de 8 costados, cercana a un cono ${ }^{73}$.

Teniendo nuevamente en cuenta el sistema de proporciones por el que, creemos, parece regirse el edificio, su altura debe estar proporcionada respecto a alguna de sus principales dimensiones. Entre las más probables, encontramos una altura equivalente a la longitud de las naves $(12,944)$ que, a la vez, resulta cercana a los $2 / 3$ de la anchura del octógono $(12,866)$, o, por el contrario, una equivalencia de la altura con respecto a la anchura del octógono $(19,3)$. Esta última posibilidad es, precisamente, la que en su momento propusiera Keil y que ahora, en base a los cálculos presentados, parece sin embargo algo excesiva ${ }^{74}$.

\footnotetext{
${ }^{72}$ Como en el caso de las bóvedas de cañón de la nave la fórmula sería $2 \pi \cdot r \cdot h$, dividido entre 2 , siendo el radio nuevamente 4 pero la hipotenusa 8 .

${ }^{73}$ Cercana a un cono en la misma medida en que el octógono de la planta se acerca al círculo (la perfección) en el cual se inscribe.

${ }^{74}$ En efecto Keil (op. cit., p. 76, fig. 63), propone una altura total del octógono y el tambor, idéntica a la de la altura total de su cubierta conoidal: 20 codos. A nuestro entender, sin embargo, yerra cuando la anchura que da al octógono es de 30 codos, por tratarse de una anchura que, como hemos podido comprobar, puede ser calculada de forma exacta mediante el uso de fórmulas geométricas y que corresponde a 19,3 codos.
} 
Otra posibilidad a considerar, sin embargo ${ }^{75}$, consiste en tomar las proporciones en planta del octógono con respecto a las de las naves (19,3 y 12,944, respectivamente), a partir de la que obtendríamos un valor exactamente equidistante desde el centro, tanto para los brazos como para el vértice de la propia cubierta ${ }^{76}$. Además, como hemos indicado esta cifra $(12,944)$, no se aleja en exceso de 12,866 , es decir, de la cifra correspondiente a 2/3 de la anchura de la base. De ser así, una sección transversal de la cubierta (fig. 7) nos daría un perfil triangular, con-

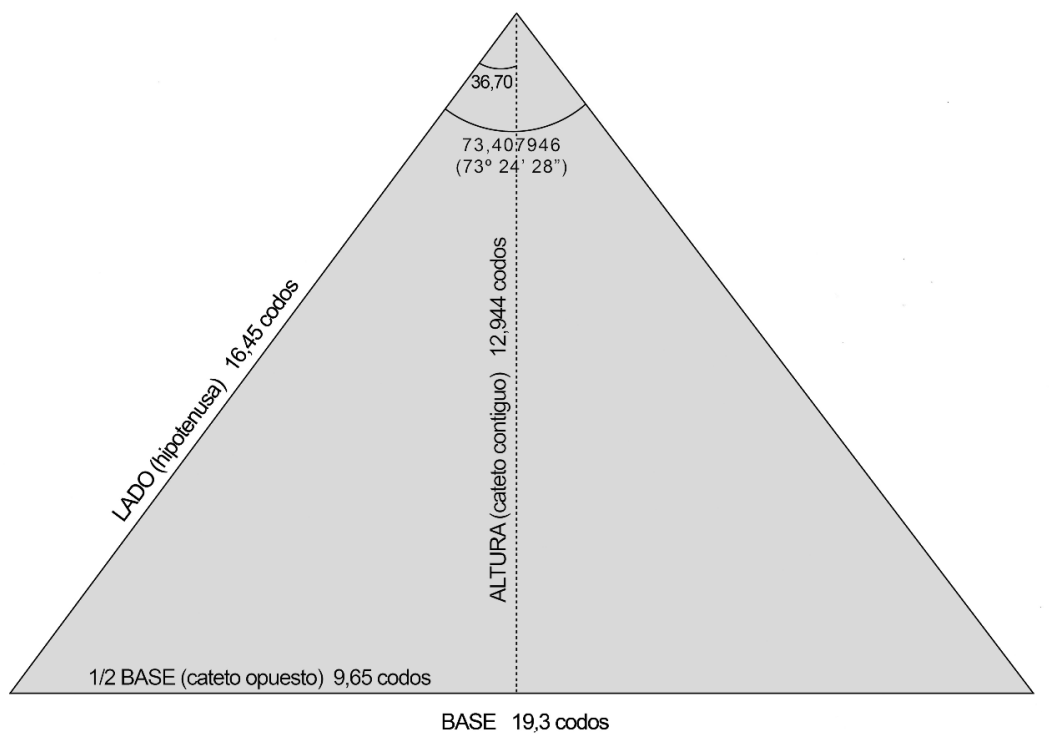

7. Esquema de las principales medidas y del cálculo del ángulo de la cubierta del octógono, en sección transversal, según $S$. Vidal.

cretamente un triángulo isósceles, cuyo ángulo sería de $73^{\circ} 24^{\prime} 28$ " ${ }^{77}$ y su volumen total (113 del área de la base $x$ altura) de 1986,6132 codos cúbicos.

Nos queda por último hacer mención del peristilo (figs. 4 y 6) para el que, como se ha indicado más arriba, ante la falta de concreción por parte de Gregorio, podría

\footnotetext{
75 Descartamos plenamente la posibilidad de aplicar una proporción equivalente a la de la anchura-altura de las naves ( 8 de anchura $\times 8+4$ de altura), en la que la altura de las cubiertas corresponde a la mitad de la anchura. En tal caso el efecto conseguido sería el de una cubierta excesivamente plana, creemos, del todo alejada a los deseos que expresa Gregorio en su texto.

${ }^{76}$ De hecho, esta misma proporción es la que parece en los edificios de planta centralizada estudiados por Trinci (op.cit., pp. 475-529), entre los que encontramos el vestíbulo de la Piazza d'Oro de la Villa Adriana de Tívoli, o la de San Vital de Rávena, siendo la que, creemos, pudo también regir al martyrium de Nisa.

${ }_{77}$ Cifra que se aleja considerablemente de la propuesta por Keil (op. cit., p. 84) de $77^{\circ} 11^{\prime} 19$ '. Para nuestro cálculo del ángulo se ha dividido el isósceles en dos, con lo que obtenemos dos triángulos rectángulos. Tomando uno de ellos se calculan sus medidas: el cateto mayor o cateto contiguo ya lo conocemos $(12,944)$ y el cateto menor o cateto opuesto es exactamente la mitad de la anchura (19'3 /2 $=9,65)$, con lo que podemos calcular la hipotenusa mediante el teorema de Pitágoras $(16,145)$. Una vez
} 
plantearse tanto su situación alrededor del martyrium, como a uno de sus lados (a modo de atrium). Como sabemos, la opción adoptada ha sido siempre la primera, considerando que el peristilo hubo de formar un cuadrado perfecto, dispuesto alrededor del martyrium, situando este último por tanto en su centro exacto ${ }^{78}$.

El texto especifica el número mínimo de columnas (40) pero no su altura (¿por considerarlo una obviedad?), pudiendo suponer que ésta pudo ser equivalente a la de las columnas del interior del edificio. En tal caso y como hemos advertido, la altura sería de ocho codos, a los que se aplicaría igualmente las proporciones pertinentes a su capitel, basa y diámetro del fuste (vid supra).

Partiendo de los datos proporcionados por el número de columnas (40) y su posible altura (8), el resultado del cálculo de las posibles dimensiones totales del peristilo depende pues del valor que concedamos a los intercolumnios. Tomando una vez más a Vitrubio en los referente a los diversos tipos de intercolumnios existentes en su época (Lib. III, 3), su cálculo parte siempre de la multiplicación del diámetro del fuste de la columna en el imoscapo o extremo inferior ${ }^{79}$. Si tenemos en cuenta que en nuestro caso las columnas miden 8 codos en total, podemos suponer que el diámetro de sus fustes en el imoscapo fuera de 1 codo y por tanto, el valor de los intercolumnios (por el momento: $x$ ) habrá de ser un múltiplo de esta última medida. El problema radica en intentar despejar dicha incógnita, sustituyendo $x$ por un valor concreto que, según Keil, equivale a $6 \operatorname{codos}^{80}$. Sin poder confirmar o refutar dicho valor, por nuestra parte creemos que es igualmente factible pensar en un sistema de medidas que siguiera unas proporciones más regulares y que, por tanto, los intercolumnios del peristilo tuvieran la misma longitud que los del octógono central, es decir 8 codos, lo cual coincidiría con la altura de las columnas y haría que las dimensiones de los propios intercolumnios fuesen iguales en altura y anchura ( $8 \times 8$ codos).

conocemos los tres lados del triángulo, el ángulo que generan la hipotenusa y el cateto contiguo (que corresponde a la mitad del ángulo del total de la estructura), se hallará mediante la fórmula: Coseno del ángulo $(\cos . A)=c / h$, es decir cos. $A=12,944 / 16,145$, o lo que es lo mismo cos. $A=0,8017342$. Por tanto, para hallar el valor del ángulo habrá de realizarse la operación opuesta al coseno (de la misma manera que al aplicar el teorema de Pitágoras hemos de emplear la raíz cuadrada como operación opuesta a una cifra elevada al cuadrado), es decir, al llamado arcoseno, lo que nos da 36,703973. Esta cifra corresponde al ángulo del triángulo rectángulo que, como sabemos, es la mitad del isósceles de la sección de la cubierta, cuyo ángulo será por tanto 36,703973 multiplicado por 2, es decir, 73,407946, o lo que es lo mismo un ángulo de 73,407946 grados. Ahora nos faltaría pasar los decimales a minutos y segundos, mediante la multiplicación por 60 (operación semejante a la efectuada para calcular el tiempo, entendiendo que 1'5 horas no son 1 hora y 50 minutos, si no 1 hora y 30 minutos. Si multiplicamos 0'5 x 60, obtendremos la cifra real de los minutos), de modo que 0,407946 x 60 nos da 24,47676 (obteniendo por tanto los minutos), y a su vez 0,47676 x 60, obteniendo 28,6056 (es decir, los segundos), con lo cual el ángulo de la sección de la cubierta del octógono sería en este caso de $73^{\circ} 24^{\prime} 28^{\prime \prime}$.

${ }^{78}$ Keil, op. cit., p. 74, fig. 62; Grabar, op. cit., p. 613, fig. 82; Smith, op. cit., fig. 27; Mango, op. cit., p. 26, fig. 24.

79 Las proporciones son de 1,5; 2; 2,25; 3 y más de 3 veces el diámetro de los fustes en su extremo inferior o imoscapo. Para las ediciones consultadas de Vitrubio vid. supra.

80 Keil, op. cit., pp. 84-85 y fig. 63. 
Aceptando una forma cuadrangular para el peristilo, hemos de partir de la existencia de un total de 40 intercolumnios, 10 por cada lado, a los que, sumándoles el grosor de las propias columnas (que serían también 40, pero desde un punto de vista óptico 11 en cada uno de los cuatro flancos, ya que las 4 columnas angulares dan a dos lados cada una), sumarían según nuestros cálculos $11+80$ codos ( $11+60$ según Keil), es decir 91 codos por cada lado ( 71 según keil), sin contar con el añadido del pasillo cubierto del peristilo que discurriría alrededor de las columnas y su correspondiente muro de cierre exterior, elementos que acabarían de redondear las cifras hasta los 110 codos en total $\left(80\right.$ según Keil) ${ }^{81}$. En tal caso el área total del peristilo ascendería a los 12100 codos cuadrados (6400 a partir de las dimensiones de Keil), resultando nuestra cifra, como veremos, más reveladora ( vid. Infra).

Si hemos considerado que la anchura total del martyrium es de casi 50 codos $(49,188)$, advertimos que el peristilo lo supera en algo más de 30 codos por cada lado $(30,406)$. Teniendo en cuenta la disposición centrada del martyrium con respecto al peristilo, el cálculo de la longitud de la zona a cielo abierto que separa al edificio principal del peristilo, resulta de restar a los 60,8 codos en que el segundo sobrepasa al primero (30,4 codos en cada lado), las dimensiones correspondientes a: el grosor de las columnas ( 1 codo), la longitud del pasillo cubierto (presumiblemente 8 codos) y el muro de cierre del peristilo (1,5 codos?), 10,5 codos en total, lo que nos proporciona una longitud de 19,906 codos para cada lado del martyrium. Como podemos advertir, dicha dimensión no resulta excesivamente alejada de los 19,3 codos correspondientes a la anchura del octógono central.

Recapitulando, los principales cálculos establecidos se resumen de la siguiente manera:

1- Planta del edificio (fig. 4):

- Octógono: 19,3 codos de anchura y 20,9 de diámetro; área 308,8 codos cuadrados.

- Absidiolos: 8 codos de diámetro y 4 de radio; área 25,13 cuadrados.

- Naves: «algo más» de 12 codos de longitud $(12,944)$ por 8 de anchura; área 103,552 codos cuadrados.

- Anchura del perímetro mural: 2 codos (3 pies).

- Total de la anchura: algo más de 47,3 codos $(49,188)$, incluyendo el grosor de los muros, sin incluirlo algo más de $43,3(45,188)$.

— Área total del espacio interior: 823,528 codos cuadrados.

${ }^{81}$ Tal vez pudo aplicarse éntasis, o sistema de corrección óptica de las proporciones, para las 4 columnas angulares del peristilo. Según Vitrubio (III, 3), éstas han de ser 1/50 parte más gruesas que el resto, para que así, por defecto de la visión humana no parezcan más estrechas que aquellas. 
2- Alzado (fig. 6):

- Naves: 8 codos de altura por 8 de anchura por «algo más» de 12 codos de longitud (12,944); volumen 828,416 codos cúbicos.

- Bóvedas de las naves: misma longitud que las naves por 8 de diámetro por 4 de radio; volumen 162,659 codos cúbicos.

- Absidiolos: 8 codos de altura por 8 de diámetro y 4 de radio; volumen (incluyendo las cubiertas) 150,7912 codos cúbicos.

- Octógono: 19,3 codos de anchura, por 19,3 codos de altura (8 hasta la imposta, +4 hasta el cenit de los arcos, $+3,3$ del sector de las ventanas, +4 del tambor); volumen 5959,84 codos cúbicos.

- Cubierta del octógono: 19,3 codos de anchura (base) por 12,944 codos de altura, ocho caras de 16,145 codos de altura cada una. Volumen 1968,6132 codos cúbicos.

— Volumen total del espacio interno: 8922,108 codos cúbicos.

3- Peristilo (figs. 4 y 6):

- Columnas: 40 en total de 8 codos de altura por 1 de diámetro (en el imoscapo).

- Intercolumnios: 8 codos por 8 de altura.

- Espacio cubierto: 8 codos de anchura.

- Muro de cierre del peristilo: 1,5 codos?

- Espacio entre el peristilo y el martyrium: 19,9 codos (nunca más de 20,85).

- Dimensiones totales del peristilo: 110 x 110 codos (80 de los 10 intercolumnios, 11 de las columnas, 16 del pasadizo cubierto -8 en cada extremo- y 3 del muro de cierre $-1,5$ en cada extremo-).

\section{CONCLUSIONES}

Como hemos podido observar, la tipología a la que corresponde el edificio capadocio es la de un martyrium cruciforme y, dentro de esta amplia denominación, a la categoría del martyrium de «cruz libre», puesto que los brazos de la cruz conforman volúmenes arquitectónicos propios, visibles desde el exterior, en lugar de estar incorporados en volumen arquitectónico que los englobe ${ }^{82}$. En dicho grupo, el ejemplo de Nisa sería uno de los más antiguos conocidos junto con el ya mencionado de S. Babilás cercano a Antioquía, por su datación dentro del último cuarto del siglo IV.

${ }^{82}$ Grabar, op. cit., pp. 152-154. 
A la misma tipología pertenecerían también otros edificios de mayor envergadura como son la iglesia de los Santos Apóstoles de Constantinopla (en su fase de época constantiniana), a la que se viene atribuyendo una planta cruciforme, fosilizada en la posterior reconstrucción justinianea ${ }^{83}$, la basílica de San Juan de Éfeso (fase del siglo V) ${ }^{84}$, así como el ya mencionado martyrium de Siquem (vid. supra). Ya a finales del siglo $\mathrm{V}$, encontramos el monumental martyrium de San Simeón Estilita en Qal'at Si'man (Siria), todavía en relativo buen estado de conservación y que, tal vez, constituye desde un punto de vista arquitectónico el edificio que más se acercaría al martyrium de Nisa. Existen, sin embargo diferencias notables entre ambos edificios, como son la cronología y las dimensiones, pero también el material empleado, puesto que en el edificio sirio observamos una construcción a base de grandes bloques de piedra perfectamente tallados y encajados, dispuestos en seco, con la consiguiente inversión en tiempo y dinero que ello debió suponer y que, como hemos advertido, Gregorio parece querer evitar ${ }^{85}$.

A la misma tipología pertenecería también un amplio grupo de edificios datados entre los siglos IV-VI, de la zona de Siria, Palestina y Asia Menor, entre los que destacarían San Sergio de Gaza o la iglesia de San Simeón Estilita el Joven cercana a Antioquía ${ }^{86}$, así como los ejemplos de Viran Chehir y Süt Kilisse, ambos en Licaonia (por tanto, en las inmediaciones de Iconium) ${ }^{87}$. Por otra parte, tendríamos otros ejemplos que confirman el éxito y la difusión de la tipología en otras regiones orientales como Crimea o Bulgaria ${ }^{88}$, y en occidente tanto en Italia ${ }^{89}$ y las Galias ${ }^{90}$, como en Hispania ${ }^{91}$.

${ }^{83}$ Vid. Krautheimer, op. cit., 1992, p. 81-82, y 535 notas 4-6, donde se trata también el tema de la enorme influencia que ejercerá este edificio ya desde el siglo IV, sin ir más lejos en los ejemplos citados por nosotros en el texto. Así mismo, Krautheimer plantea el problema de las diferentes reconstrucciones que se han dado del primer Apostoleion de Constantinopla, defendiendo la propuesta de la planta centralizada cruciforme, con cubierta cónica, en base a las propias palabras de Eusebio de Cesarea (Vita Constantini, IV, 58-60), ed. española A cargo de M. Gurruchaga, 1994 (Biblioteca Clásica Gredos, 190), pp. 380-383).

${ }^{84}$ Ibid., pp. 81-82, en base esencialmente a los trabajos de Keil y Hörmann del Instituto Arqueológico Austríaco, publicados en 1951 (Forschungen in Ephesos, IV, 3, Viena, 1951, p. 200 y ss.).

${ }^{85}$ Sin ánimo de ser exhaustivos vid. Lassus, 1947, p. 129 ss.; Grabar, op. cit., pp. 156-157; Mango, op. cit., pp. 79-89; Krautheimer. op. cit., 1992, pp. 167-183 y p. 549, n. 26. Por otra parte, el edificio sirio posee el tres naves en sus brazos, con la consiguiente aparición de cuatro espacios trapezoidales para enlazar el octógono central con las cuatro exedras o absidiolos que por este motivo quedan considerablemente más pequeñas.

${ }^{86}$ Smith, op. cit., p. 111.

${ }^{87}$ Grabar. op. cit., p. 157 y n. 1.

88 Ibid., pp. 158-159.

89 Ibid., p. 160, concretamente S. Nazario de Milán, S. Abiondio de Como y S. Tiburcio de Roma.

90 Ibid., citando Sta. Genoveva, de París y Sta. Cruz y S. Vicente de la misma ciudad.

${ }^{91}$ Ibid., pp. 160-161. Para Hispania Grabar habla de Santa Comba de Bande y San Fructuoso de Montelios. Para santa Comba de Bande y su problemática vid. Schlunk-Hauschild, 1978, pp. 218-220; Godoy, op. cit., 325-327; Utrero, 2006, pp. 581-583, con la principal bibliografía. Para San Fructuoso de Montelios vid. Schlunk-Hauschild, op. cit., pp. 209-211; Utrero, 2006, pp. 607-610, con la principal bibliografía. 
En cuanto a las principales relaciones numéricas que posee el edificio de Nisa, podemos constatar que sin duda posee especial relevancia el 8 , siendo el número de lados del octógono, el número de codos de han de medir tanto los lados del mismo como la anchura de las naves y los absidiolos. 8 son también las columnas que han de estar delante de los 8 pilares angulares del octógono, 8 los arcos que las mismas han de sustentar y de la misma forma, 8 son los lados de la cubierta «conoidal» del octógono. Además, cuando se menciona la longitud de las naves no se dice directamente su cifra, sino que éstas han de ser algo más de 1'5 veces la anchura, o sea algo más de una vez y media 8.

El resto de medidas mencionadas se relacionan con el 8 , así el número de brazos y el número de absidiolos son 4, la mitad de 8, y 40 han de ser las columnas del peristilo, siendo 40 la multiplicación de $8 \times 5$. Finalmente, el grosor de la construcción es de 3 pies, que equivalen a 2 codos, o lo que es lo mismo 8/4.

El tema del simbolismo de los números tiene sin duda una clara sistematización con los Pitagóricos, para los cuales el número es el principio de todas las cosas. Esta concepción mística del número fue, como hemos visto tema clave para Platón (Timeo), Filolao, Nicómaco de Gerasa, Vitrubio o Plotino ${ }^{92}$. Sin embargo esta misma noción perdura en los siglos posteriores como demuestra San Isidoro y su Liber Numerorum $^{93}$ que, a su vez, se basaría en San Agustín ${ }^{94}$ y en el que aparecen reflejados muchos conceptos, sino originados sí al menos sistematizados por los Pitagóricos. De este modo el ocho, el que ahora más nos interesa, además de perfecto por estar generado por la doble multiplicación del $2\left(2^{3}\right.$, siendo el primer y único cubo existente en la década), seria también santo y además, relacionado con la resurrección ${ }^{95}$.

Quisiéramos llamar por último la atención, sobre el hecho de que existe en el martyrium de Nisa una clara progresión de la multiplicidad a la unidad, a medida que el edificio se eleva en alzado. Esa direccionalidad de lo múltiple a lo unitario, que aparece reflejada en la Enéada VI de Plotino como el camino que el Ser ha de realizar hacia su interior, se corrobora al observar cómo de la multiplicidad del peristilo (40 columnas), se pasa a los ocho espacios «periféricos» del edificio principal, los cuales convergen en un único espacio central. Este espacio central a su vez, tiene en su base ocho costados, es decir la multiplicidad en la unidad (representa por tanto lo más perfecto dentro del mundo imperfecto), sin embargo, al ir elevándose la multiplicidad va disminuyendo para acabar en el cenit de su cubierta en un único punto (la mónada), alcanzando así de un modo pleno la unidad (lo divino y perfecto).

\footnotetext{
92 De un modo especial la Enéada X. Vid. los correspondientes volúmenes de las ediciones citadas de Armstrong y Mínguez.

${ }^{93}$ Migne, PL, LXXXIII, cols. 179-200.

${ }^{94}$ Como sabemos, no se conserva ningún Liber numerorum de San Agustín, aunque es muy posible que existiera. Con todo, podemos conocer de manera parcial sus ideas sobre esta cuestión gracias a diversos pasajes de su Civitate Dei, así en el libro XI, cap. XXX para el número 6, o en el lib. XX para el 10. Para la incidencia del neoplatonismo en esta obra de San Agustín vid. Rusell, 1981, pp. 160-170.

${ }_{95}$ Migne, PL, LXXXIII, col. 189.
} 


\section{BIBLIOGRAFÍA}

ALTANER, B., 1956: Patrología, Madrid.

ARIAS PÁRAMO, L., 1989: «Geometría y proporción en la arquitectura prerrománica asturiana: la iglesia de San Julián de los Prados", XXXIX Corso di Cultura sull'Arte ravennate e bizantina, Rávena, pp. 11-62.

ARMSTRONG, A H., 1984: Plotinus, Enneads, VII vols., Cambridge (Mass.)-Londres.

BARRAL, X., 1981: L'art pre-romànic a Catalunya. Segles IX-X, Barcelona.

BELL, E.T., 1949: Historia de las Matemáticas, México D.F. (ed. original inglesa Nueva York, 1940).

BIRNBAUM, A., 1913: «Die Oktogone von Antiocheia, Nazianz und Nyssa», Repertorium für Kunstwissenschaft, 36, pp. 181-204.

BLÁNQUEZ, A., 1995: Vitruvio. Los diez libros de arquitectura, Barcelona.

BURNES, J., 1986: The Presocrathic Philosofers, Londres.

COLLETTE, J.-P., 1985: Historia de las matemáticas, I, Madrid, 1985 (ed. original francesa París, 1973).

COMPOSTELLA, C., 1990: «Dittico Trivulcio», Milano capitale dell'Impero Romano, 286-402 d.c., Milán, pp. 342-343.

CORBALÁN, F., 2010: La proporción áurea. El lenguaje matemático de la belleza, Madrid.

CRISCUOLO, R., 1981: Gregorio di Nissa. Epistole, Nápoles.

D'OOGE, M. L.-ROBBINS, F. C.-KARPINSKI, L. CH, 1926: Nichomachus of Gerasa. Introduction to Arithmetic, Studies, Humanistic Series, XVI, Nueva York.

DÖLGER, F. J. «Zur Simbolik des altchristlichen Taufhauses», Antike un Christentum, IV, 1933, pp. 153187.

DONCEEL-VOÛTE, P., 1988: Les pavements des églises byzantines de Syrie et du Liban. Décor, archeologie et liturgie, Lovain-la-Neuve.

DUVAL, Y., 1988: Auprès des Saints, corps et âme. L'inhumation «ad sanctos» dans la chrétienté d'Orient et d'Occident du IIlè au Vilè siècle, París.

GHYKA, M. C., 1968: El número de oro. Ritos y ritmos pitagóricos en el desarrollo de la civilización occidental, II vols, Barcelona.

GODOY, C., 1995: Arqueología y liturgia. Iglesias hispánicas (siglos IV al VIII), Barcelona.

GODOY, C.-TUSSET, F., 1994: «El Atrium en las Vitas SS. Patrum Emeritensium ¿una fórmula de la llamada arquitectura del poder?», Archivo Español de Arqueología, 67, pp. 209-221.

GRABAR, A, 1946: Martyrium. Recherches sur le culte des reliques et l'art chrétien antique, III vols., París.

GROS, P., 1983: Vitruvius. On architecture, II vols., Cambridge (Mass.)-Londres.

GROS, P., 1969: Vitruve, París, Budé (col. Les Belles Lettres).

GURRUCHAGA, M. (ed.), 1994: Eusebio de Cesarea. Vida de Constantino, (Biblioteca Clásica Gredos, 190), Madrid.

IVÁNKA, E. von, 1992: Platonismo Cristiano. Recezione e trasformazione del Platonismo nella Patristica, Milán (ed. original alemana Einsiedeln, 1964).

JANERAS, S., 1986: Pelegrinatge d'Egèria, Barcelona.

JUNECKE, H., 1983: Proportionen frühchristlicher Basiliken des Balkan im Vergleich von zwei unterschiedlichen Meßverfahren. Proportionen der Hagia Sophia in Istambul, Tübingen.

KEIL, B., 1903: «Der Brief Gregors von Nyssa an Anphilochios», en: STRZYGOWSKY, 1903, pp. 77-90 y figs. 62-63.

KIRK, C. S.-RAVEN, J. E.-SCHOFIELD, M., 1994: Los filósofos presocráticos. Historia crítica con selección de textos, Madrid, 1994 (ed. original inglesa, Cambridge, 1957).

KLOCK, C., 1983: «Architektur im dienste der Heiligenverehnung. Gregor von Nyssa als Kirchenbauer (Ep. XXV)», Proceedings of the fifth colloquium on Gregory of Nyssa (Patristic Monograph Series, 12), Cambridge (Mass.).

KRAUTHEIMER, R., 1942: «Introduction to an "iconography of mediaeval architecture" », Journal of the Warburg and Courtauld Institutes, V, pp. 1-33.

KRAUTHEIMER, R., 1992: Arquitectura paleocristiana y bizantina, Madrid, (ed. original inglesa, Harmondsworth, 1965).

LASSUS, J., 1947: Sanctuaires chrétiens de Sirie. Essai sur la gènese, la forme et l'usage liturgique des edifices du culte chrétien en Sirie du Illè siècle à la conquête musulmane, París.

MANGO, C., 1966: «Isaurian Builders», Polychronion. Fetschrift F. J. Dölger, , pp. 358-365.

MANGO, C., 1975: Arquitectura bizantina, Madrid (1르 ed. original Milán, 1974).

MATEO-SECO, L. F.-MASPERO, G. (eds.), 2010: The Brill Dictionary of Gregory of Nyssa, LeidenBoston. 
MARAVAL, P., 1990: Grégoire de Nysse. Lettres, París (Sources Chrétiennes, $\mathrm{n}^{\circ}$ 363).

MIGNE, J. P., 1863: Patrología Graeca, vols. XLIV-XLVI, Gregorii episcopi nysseni, Opera quæ reperiri potuerunt omnia, París.

MIGNE, J. P., 1862: Patrología Latina, vol. LXXXIII, Sancti Isidori, Hispalensis Episcopi, Opera Omnia, Tomus Quintus, París (espec. cols. 179-200).

MíNGUEZ, J. A, 1967: Plotino. Eneada quinta, Aguilar, Buenos Aires.

MíNGUEZ, J. A, 1990: Platón. Obras completas, Madrid (1ª ed. 1966).

O'MEARA, 1989: Pitagoras revived. Mathematics and Philosophy in Late Antiquity, .

OLIVIER J. L., 1995: Marco Pulio Vitruvio Polión. Los diez libros de Arquitectura, Madrid.

QUASTEN, J., 1962: Patrología, vol. II, La edad de oro de la patrística griega, Madrid (ed. original inglesa, Utrech-Bruselas, 1960).

PARRA LEÓN, M., 1966: Pitágoras. Fundador de las ciencias matemáticas, Caracas.

PASQUALI, G., 1925: Gregorii Nysseni Epistulae, Berlín.

RESTLE, M., 1979: Studien zur frühbyzantinischen Architektur Kappadokiens, Viena.

SANTAMARTA DEL RÍO, S.-FUERTES LANERO, M., 1988: Obras completas de San Agustín, La ciudad de Dios, II vols., Madrid ( $4^{\mathrm{a}} \mathrm{ed}$.).

SAXER, V., 1980: Morts, Martyrs, Reliques en Afrique chrétienne aux premiers siècles, París.

SCHLUNK H.-HAUSCHILD, Th., 1978: Hispania Antiqua. Die Denkmaler der frühchristlichen und westgotischen Zeit, Mainz am Rhein.

SILVAS, A. M., Gregory of Nissa: The Letters. Intoduction Translation and Commentary, Leiden-Boston, 2007.

SMITH, E. B., 1950: The Dome. A study in the history of ideas, .

STRZYGOWSKY, J., 1903: Kleinasien. Ein Neuland der Kunstgechichte, .

RUSELL, R., 1981: «The role of neoplatonism in St. Agustine's De Civitate Dei», Neoplatonism and Early Christian Thought. Essays in honour of A. H. Armstrong, Londres, pp. 160-170.

TEJA, R., 1974: Organización económica y social de Capadocia en el siglo IV, según los Padres capadocios, Salamanca.

TEJA, R., 1991: «Gregorio de Nisa arquitecto y empresario», Antigüedad y cristianismo, VIII, Murcia, pp. 67-69.

TRINCI, R., 1984: «La geometria e la sezione aurea nel S. Vitale di Ravenna e in S. Apollinare in Clase», XXXI Corso di Cultura sull'Arte ravennate e bizantina, Rávena, pp. 475-540.

ULBERT, T., 1986; Resafa II. Die Basilika des Heiligen Kreuzes in Resafa-Sergiupolis, Mainz am Rhein.

UTRERO, M. A., 2006: Iglesias tardoantiguas y altomedievales en Análisis arqueológico y sistemas de abovedamiento, (Anejos de Archivo Español de Arqueología, XL), Madrid.

VIVES, J., 1991: Gregori de Nissa. Vida de Moisès, Barcelona (Col. Clàssics del Cristianisme). 